\title{
THE SPATIAL DISTRIBUTION OF DEVELOPMENT ACROSS AFRICA AND ITS UNDERLYING SUSTAINABILITY CORRELATIONS
}

\author{
by \\ Joshua Ali \\ Honours Bachelor of Arts in Environment and Urban Sustainability, Ryerson University, 2018
}

\author{
A Major Research Paper Presented to Ryerson University \\ in partial fulfillment of \\ the requirements for the degree of \\ Master of Spatial Analysis (MSA) \\ in the program of \\ Spatial Analysis
}

Toronto, Ontario, Canada 2019

(C) Joshua Ali, 2019 


\section{Author's Declaration for Electronic Submission of an MRP}

I hereby declare that I am the sole author of this MRP. This is a true copy of the MRP, including any required final revisions.

I authorize Ryerson University to lend this MRP to other institutions or individuals for the purpose of scholarly research.

I further authorize Ryerson University to reproduce this MRP by photocopying or by other means, in total or in part, at the request of other institutions or individuals for the purpose of scholarly research.

I understand that my MRP may be made electronically available to the public. 
Joshua Ali

Master of Spatial Analysis (MSA), Ryerson University

2019

THE SPATIAL DISTRIBUTION OF DEVELOPMENT ACROSS AFRICA AND ITS UNDERLYING SUSTAINABILITY CORRELATIONS

\begin{abstract}
The realization of the critical issues that have been faced by the global community has put a particular focus on assessing the sustainable development of countries. Africa is an area that needs an assessment of sustainable development. With Africa holding over $52 \%$ of the world's natural resources reserves, it is imperative to assess the sustainable development of the countries. The study evaluated what the underlying and spatial distribution on sustainable development was in Africa. Six dimensions of underlying sustainability and three significant signs of spatial autocorrelation were found. This provided information about the sustainability vulnerabilities within Africa. With the majority of the underlying dimensions displaying a socioeconomic focus on sustainability. Showing the collected indices result in a lack of coverage on the environmental side across the countries of Africa.
\end{abstract}




\section{Acknowledgments}

I would like to thank Dr. Richard R. Shaker for the support and guidance he has given me since my first year and throughout the writing of this Major Research Paper. I would also like to thank my family, friends and Julia Policelli for continually supporting me throughout my academic career.

I would also like to dedicate this paper to the memory of my grandfather who passed away during the writing and research of this paper. I will greatly miss your insight, guidance and our conversations. 


\section{Table of Contents}

Author's Declaration for Electronic Submission of an MRP ............................................................... ii

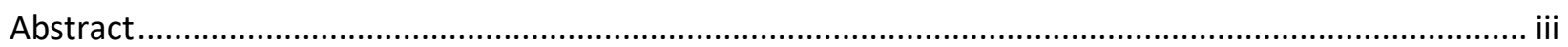

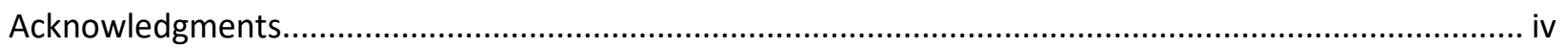

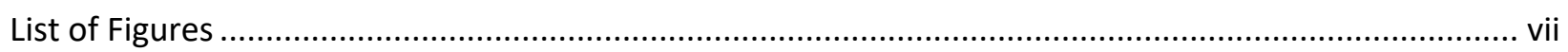

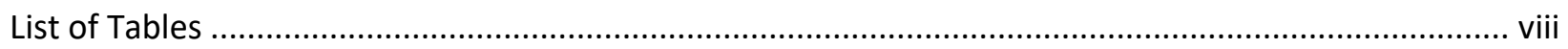

1: Introduction

1.1. Introduction

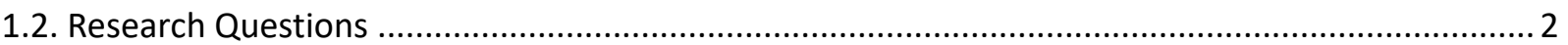

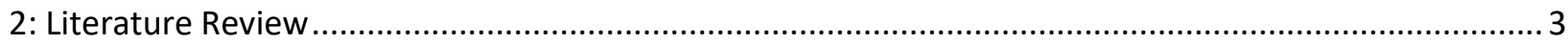

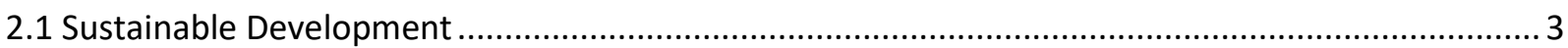

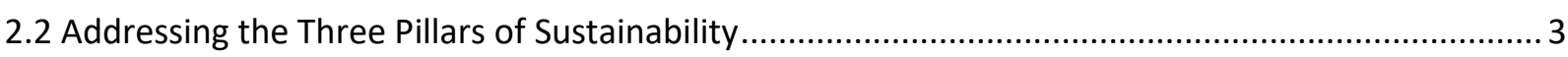

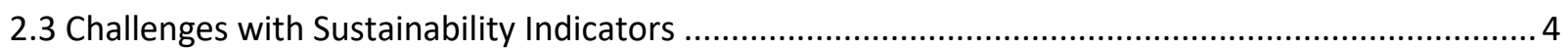

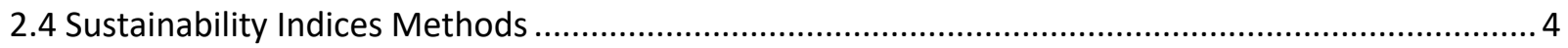

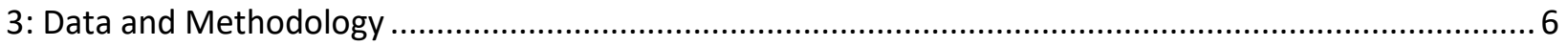

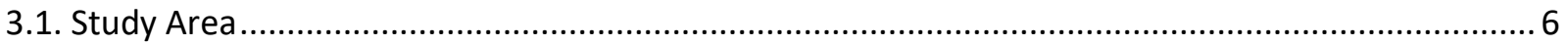

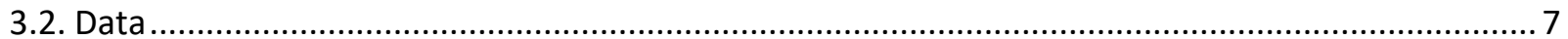

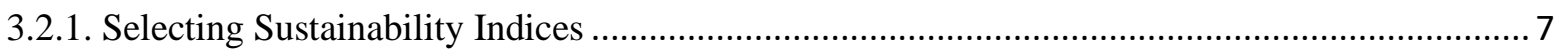

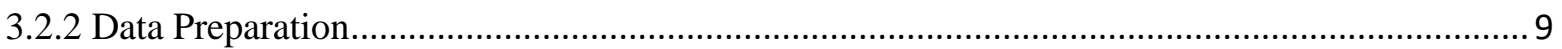

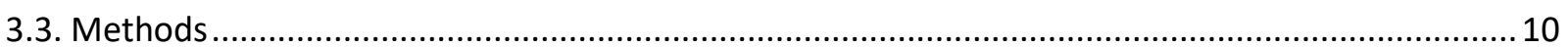

3.3.1. Factor Analysis - Revealing Underlying Sustainability Dimensions .................................... 10

3.3.2. Global and Local Moran's I Statistic - Assessing Spatial Autocorrelation ............................. 10

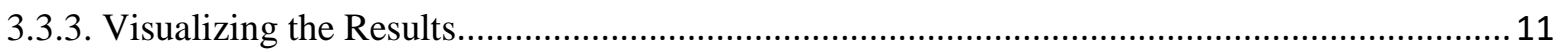

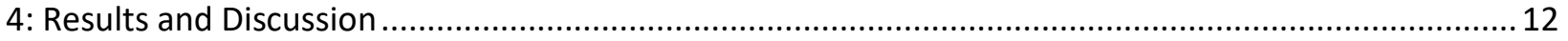

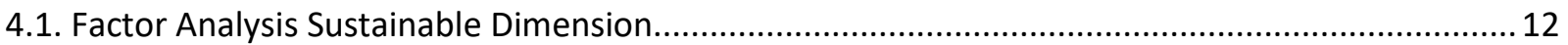

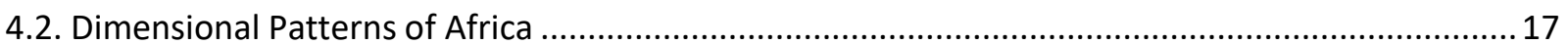

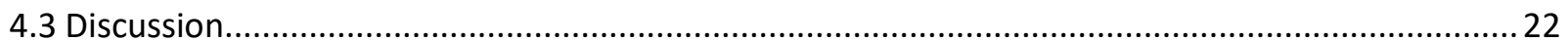

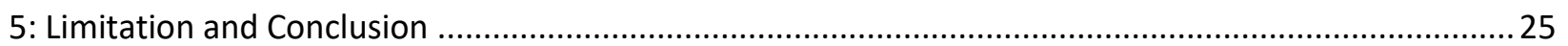

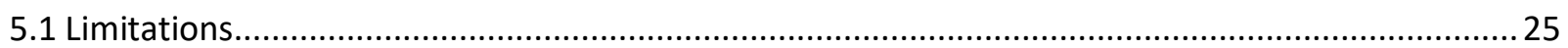

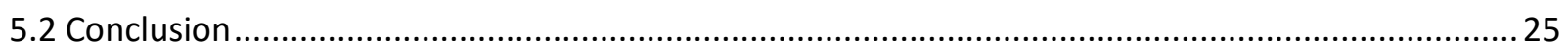

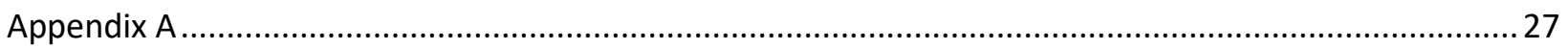

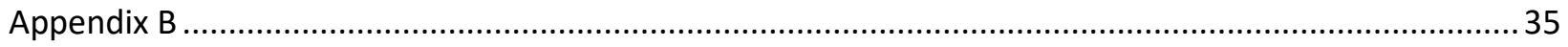

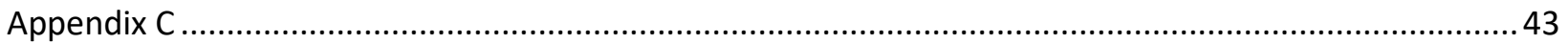


References .. 


\section{List of Figures}

Figure 1: Map of the 53 selected African countries for the study.

Figure 2: Spatial distribution of factors scores for the first three dimensions (Eigenvalues $>1$ ) across Africa. The dimensions are as followed F1, human prosperity; F2, political instability \& economic freedom; F3, environmental wealth.

Figure 3: Spatial distribution of factors scores for the last three dimensions (Eigenvalues $>1$ ) across Africa. The dimensions are as followed F4, socioeconomic trade-offs \& risk; F5, generosity \& environmental trade-offs; F6, aspiring sustainability.

Figure 4: Local Anselin Moran's I index of spatial association displaying clustering of the six factors across Africa. The factors are as followed, F1, human prosperity; F2, political instability \& economic freedom; F3, environmental wealth.

Figure 5: Local Anselin Morans's I index of spatial association displaying clustering of the six factors across Africa. The factors are as followed, F4, socioeconomic vulnerabilities \& risk; F5, generosity \& environmental trade-offs; F6, aspiring sustainability. 


\section{List of Tables}

Table 1: Contains descriptive and statistical metadata on the 30 sustainable development indices before, data transformations and analysis were conducted.

Table 2: Loading of the 30 sustainable development indices derived from the factor analysis with

(varimax rotation method). Each index was assigned to the factor with the strongest correlation. The three strongest indices are in bold type and were mainly used........................................................ 12

Table 3: Spatial autocorrelation results from Global Moran's I analysis for the six factor dimensions..... 17 


\section{1: Introduction}

\subsection{Introduction}

The realization of the critical issues that have been faced by the global community has put a particular focus on assessing the sustainable development of countries. To improve efforts that have been made, it is essential to understand what areas need improvement. Indices have been a great way to do this. Indices make it easier to know how well countries are doing in terms of sustainability. Many indices are taken from parts of the three pillars of sustainability (economic growth, social equity and environmental integrity); however, these three components are not drawn upon as a whole. In past decades, there have been hundreds of indices like this made. Thus, the oversaturation of sustainability indices has resulted in an unclear picture of the countries sustainable development (Shaker, 2018). With this in mind, the oversaturation of indices creates the challenge of interpreting the data obtained since it is so vast. Therefore, to combat these issues, researchers have used multivariate analysis on indices. First, this reduces the oversaturated data in smaller, more manageable variables. Second, this allows for the ability to consider multiple sustainability indices that encompass the three pillars of sustainability. All in all, creating a clear picture of how well a country is doing in terms of sustainable development.

This research paper will be filling a gap within sustainable development indices by conducting a multivariate analysis on 30 sustainable development indices across 53 of 54 residing countries of Africa. Africa is an area that is lacking research and in need of an assessment of sustainable development. The land is stricken with poverty being the poorest inhabited continent in the world. For instance, $60 \%$ of the population within SSA alone suffering from poverty (Worldatlas, 2016; Dialga, 2018). Also, Africa has the highest malnourished population in the world, with 1 out of 3 people suffering from hunger (Schlenker, W., \& Lobell, B., 2010). With this in mind, the malnourished inhabitants could increase due to the impacts of climate change. Influences such as elevated temperatures can reduce the time of harvesting seasons, thus limiting the crop yield inflating the issues of food security within the country (Schlenker, W., \& Lobell, B., 2010). 
Additionally, in terms of the extraction of resources, Africa holds over $52 \%$ of the world's natural resource reserves (Dialga, 2018). The majority of the world's natural resources being in one continent, it is critical to ensure that it is extracted at a sustainable rate for the present and future generations. For these reasons, Africa needs a sustainable development index, to understand how well the countries are doing on the three pillars of sustainability, and to help locate areas that are in need.

The data collected and used are 30 sustainability indices that fall under one of the three pillars of sustainability. With the data obtained a multivariate factor analysis will be used to determine what the underlying sustainability themes are for Africa. The report will also be looking at whether the results obtained are spatially autocorrelated in any way. Thus, the results from the analysis were mapped for better interpretation of the overall sustainability of the countries.

\subsection{Research Questions}

1. Are there underling sustainable development dimensions within Africa?

2. Of the three pillars of sustainability which areas will be most prominent within a collection of sustainability indices?

3. Will there be spatial autocorrelation between the underlying sustainable development dimensions?

The outcomes of this paper will be a crucial component for helping to understand what areas and countries within Africa lack in terms of sustainable development. By using this report to help pinpoint weaknesses within Africa will help guide decision making for the future. 


\section{2: Literature Review}

\subsection{Sustainable Development}

The notion of what is sustainable development has been around for over 3 decades now. With the first global action to address issues affecting the global community being brought up in the World Commission on Environment and Development: Our Common Future in 1987. The report was the call to action in creating a sustainable future that looked at socioeconomic development and environmental protection. This report described the first definition of sustainable development as "development that meets the needs of the present without compromising the ability of future generations to meet their own needs" (WECD, 1987). Having a better understanding of sustainable development has still resulted in struggles from decision-makers across countries to develop long term strategies to promote sustainable development (Malbert, 1998).

The discussion on sustainable development continued from the United Nations Conference on Environment and Development Agenda 21. This conference which took place in Rio de Janerio 1992, further emphasized the issues that are being faced by the global community (Chichilnisky, 1997). Agenda 21 explained the importance to collect sustainable development indicators and indices so that countries can begin to measure their development (UN, 1992). As pointed out by other studies, (Shaker, 2015; Shaker, 2018) there was a great increase of indices and indicators after the Rio summit from both the private and public sectors. Indicators collected were on a wide range of social, economic and environmental aspects. The United Nations even released another report going over a core set of 50 sustainable development indicators from a collection of 96 (UN, 2007).

\subsection{Addressing the Three Pillars of Sustainability}

Sustainability is a concept that has been hard to define. Its core concept is made up of a balance of three-dimensional pillars which are social, economic and environment. The three dimensions, known as the pillars of sustainability, represent that responsible development requires that these three areas need to be assessed (Steiner, \& Posch, 2006; Hansmann, Mieg, \& Frischknecht, 2012). All three concepts being implemented on their own in the past. For example, the environmental movement has gone back as far as the late-1800s deeply rooted 
within the urban and industrial sectors (Gottlieb, 1993). The 1970s represented a turning point for the environmental movement and the late 1980s being a turning point regarding sustainability as a whole (Pezzoli, 1997). It was at this point, the importance of considering social, economic and environmental factors together would lead to more favourable results for sustainability.

\subsection{Challenges with Sustainability Indicators}

With sustainability still being known as a term without a clear definition has resulted in a weakness with an unbalanced focus between the social, economic and environmental sides of sustainability indicators (Pissourious, 2013; Verma, \& Raghubanshi, 2018). Sustainability has no universally accepted definition (Turcu, 2013), has also led to an abundance of different collection methods for indicators. The problem is that researchers who specialize in their field would derive their own interpretation of what sustainability meant (Tanguay, Rajaonson, Lefebvre, \& Lanoie, 2010). The abundance of indices created from different interpretations of sustainability has led to an increase in confusion when trying to understand the results of sustainability indicators. A recent analysis that has been adopted by researchers is making it easier to derive better interpretations from a collection of sustainability indicators (Verma, \& Raghubanshi, 2018).

\subsection{Sustainability Indices Methods}

Decades later, hundreds of sustainability indicators have been recorded from both the public and private sectors. Sustainability indicators have been used for studies in 2 different ways. The first is to use analysis on a single measure such as ecological footprint to analyze countries (Bilgili, \& Ulucak, 2018). The second method is accomplished by aggregating multiple sustainability indicators to describe the sustainable development of a country (Lee, Y., \& Huang, C., 2007; Shaker, 2015; Dialga, 2018; Shaker, 2018). The methods that used multivariate factor analysis derived from a principal component analysis were the most useful when interpreting the results (Huang, Wu, \& Yan, 2015; Mascarenhas, Nunes, \& Ramos, 2015). The sustainability indicators that were selected for these studies contained the three pillars of sustainability (environment, social and economic) to create a sustainability index for their respective study areas. 
The combination of indicators used with the sustainability or sustainable development index varies study by study due to the time/resources to collect measurements and number of indicators available for their research. In a previous research study (Lee, Y., \& Huang, C., 2007), a sustainability index was done for Taipei to determine if the country was working towards sustainable development. Over 51 sustainability indicators were identified and organized under four different categories. The sustainability indicator groups were economic, social, environment and institutional dimension. This fourth dimension being a further distinction of social aspect focusing on the governing policies and plans within the countries (Lee, Y., \& Huang, C., 2007). The objective of this analysis was to determine if the country was moving towards sustainable development.

Another study that was done on a larger scale looked at most countries within the Americas. This study used 31 known indices and compared them to the 30 countries selected within America. The countries were scored based on the overall sustainable development conditions; this was called the Mega-Index of Sustainable Development (MISD). This research used multivariate analysis to discover "7 hidden sustainability dimensions" (Shaker, 2018) from a collection of sustainability indices. From the results, the data were normalized to 0 to 100 (worst to best) allowing for better interpretation of the results when mapping the data authorized for a higher understanding of the subject. Making it easier to locate what was considered the winning countries and what was losing countries by seeing their spatial distribution on the map (Shaker, 2018). This process has been overlooked by other studies that have attempted to do more significant indices (Dialga, 2018). Having the mapping element will significantly improve the planning that can come from the research done on sustainable development. 


\section{3: Data and Methodology}

\subsection{Study Area}

The study area makes up the majority of Africa which is the second most populated continent on the planet that spans over 30 million square kilometres and contains $12.7 \%$ of the earth's land (Worldatlas, 2016). The main drives for the economy are, agriculture and mining due to the vast land and sizeable natural resource deposits (Schlenker, W., \& Lobell, B., 2010; Dialga, 2018). The study area is comprised of 53 of the 54 African countries. The 53 African countries that were selected was due to most data collected on them were available. The only country that was excluded from the study was Somalia.

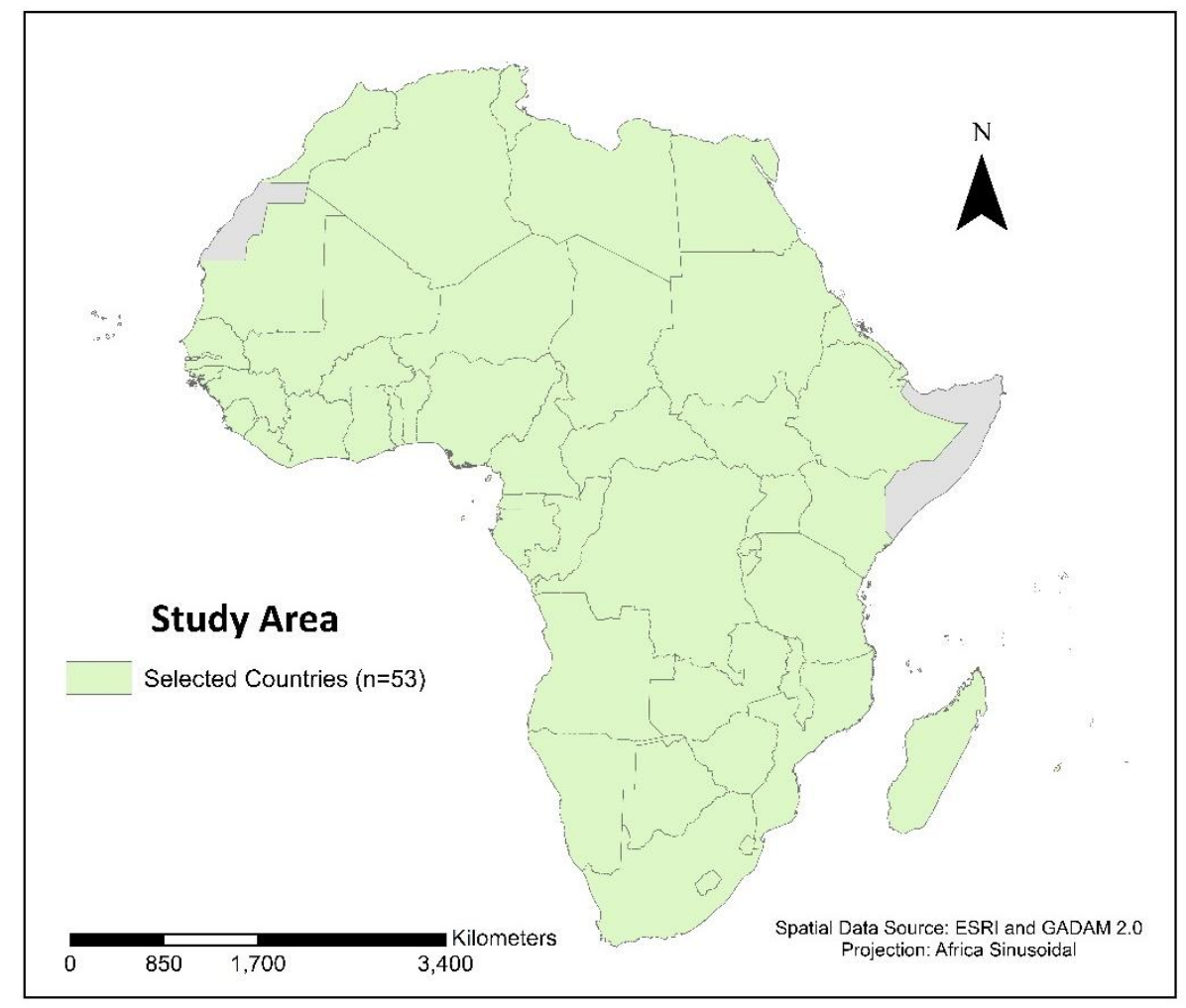

Figure 1: Map of the 53 selected African countries for the study. 


\subsection{Data}

\subsubsection{Selecting Sustainability Indices}

The data being used for this analysis are sustainability indices that have been conducted on 53 African countries. These indices were collected from websites databases such as World Bank Open Data. Also, the literature was used to obtain index scores such as the Ecosystem Wealth Index from The Wellbeing of Nations by Robert Prescott-Allen 2001.

The 30 sustainability indices chosen, relate to the three pillars of sustainability (economic growth, social equity and environmental integrity) so that they would be equally represented. After the collection of sustainability indices, there were very few representing all three pillars of sustainability on their own (Shaker, 2018). By having 30 sustainability indices collected, will ensure that the results best represent the sustainable development dimensions of the countries in Africa. The range of indices compiled for Africa is from 2001 to 2018 with the majority of the index being from 2016 or higher.

The following are the 30 sustainable development indices used for the analysis: Child development index (CDI; SCF, 2012), child health indicator (CHI; CIESIN, 2015), corruption perception index (CPI; TI, 2016), democracy index (DI; EIU, 2018), ecological footprint (ECF; GFN, 2016), economic freedom (EF; HF, 2019), economic vulnerability index (ECVI; REVI, 2016), ecosystem stress index (ECSI; Prescott-Allen, 2001), ecosystem well-being index (EWI; PrescottAllen, 2001), education index (El; UNDP, 2013), environmental performance index (EPI; SDAC, 2018), environmental sustainability index (ESI; SDAC, 2005), environmental vulnerability index index (ENVI; SDAC, 2004), global gender gap (GGG; WEF 2018), global peace index (GPI; IEP, 2019), gross domestic product (GDP; WB, 2017), happy planet index (HPI; HPI, 2016), human development index (HDI; UNDP, 2017), human sustainable development index (HSDI; OW, 2010), human wellbeing index (HWI; Prescott-Allen, 2001), legatum prosperity index (LPI; LI, 2018), natural resource protection indicator (NRPI; NRPI, 2017), notre dame global adaptation initiative index (NDGAIN; NDAII, 2017), social progress index (SPI; SPI, 2018), sustainable development goals index (SDGI; SDGI, 2018), sustainable society index - economic wellbeing (SSIEC; SSIEC, 2016), sustainable society index - environment wellbeing (SSIEN; SSIEN, 2016), 
sustainable society index - human wellbeing (SSIH; SSIH, 2016), world giving index (WGI; CAF, 2013), and world risk index (WRI; BEH, 2018).

Table 1: Contains descriptive and statistical metadata on the 30 sustainable development indices before, data transformations and analysis were conducted.

\begin{tabular}{|c|c|c|c|c|}
\hline Abbreviation & Description & Range & $\begin{array}{l}\text { Originally } \\
\text { Completed }\end{array}$ & Reference \\
\hline$\overline{C D I}$ & Child Development Index & (Best) $0-100$ & 93 & SCF (2012) \\
\hline $\mathrm{CHI}$ & Child Health Indicator & 0-100 (Best) & 96 & CIESIN (2015) \\
\hline CPI & Corruption Perception Index & 0-100 (Best) & 94 & TI (2016) \\
\hline $\mathrm{DI}$ & Democracy Index & $0-10$ (Best) & 96 & EIU (2018) \\
\hline ECF & Ecological Footprint & (Best) 0.01-3.73 gha/pers & 98 & GFN (2016) \\
\hline EF & Economic Freedom & $0-100$ (Best) & 100 & HF (2019) \\
\hline ECVI & Economic Vulnerability Index & (Best) 0-100 & 98 & REVI (2016) \\
\hline ECSI & Ecosystem Stress Index & (Best) $0-100$ & 98 & Prescott-Allen (2001) \\
\hline EWI & Ecosystem Well-being Index & $0-100$ (Best) & 98 & Prescott-Allen (2001) \\
\hline $\mathrm{EI}$ & Education Index & $0-1$ (Best) & 100 & UNDP (2013) \\
\hline EPI & Environmental Performance Index & 0-100 (Best) & 100 & SDAC (2018) \\
\hline ESI & Environmental Sustainability Index & 0-100 (Best) & 81 & SDAC (2005) \\
\hline ENVI & Environmental Vulnerability Index & (Best) 174.194-446.154 & 100 & SDAC (2004) \\
\hline GGG & Global Gender Gap & $0-100$ (Best) & 70 & WEF (2018) \\
\hline GPI & Global Peace Index & (Best) 1.07-3.57 & 92 & $\operatorname{IEP}(2019)$ \\
\hline GDP & Gross Domestic Product (\$ US Millions) & $623-1,029,312$ (Best) & 96 & WB (2017) \\
\hline HPI & Happy Planet Index & $0-100$ (Best) & 66 & HPI (2016) \\
\hline HDI & Human Development Index & $0-1$ (Best) & 100 & UNDP (2017) \\
\hline HSDI & Human Sustainable Development Index & $0-1$ (Best) & 92 & OW (2010) \\
\hline HWI & Human Wellbeing Index & 0-100 (Best) & 100 & Prescott-Allen (2001) \\
\hline LPI & Legatum Prosperity Index & 0-100 (Best) & 83 & LI (2018) \\
\hline NRPI & Natural Resource Protection Indicator & 0-100 (Best) & 98 & NRPI (2017) \\
\hline NDGAIN & Notre Dame Global Adaptation Initiative Index & 0-100 (Best) & 96 & NDAII (2017) \\
\hline SPI & Social Progress Index & $0-100$ (Best) & 81 & SPI (2018) \\
\hline SDGI & Sustainable Development Goals Index & 0-100 (Best) & 87 & SDGI (2018) \\
\hline SSIEC & Sustainable Society Index - Economic Wellbeing & 1-10 (Best) & 85 & SSIEC (2016) \\
\hline SSIEN & Sustainable Society Index - Environment Wellbeing & $1-10$ (Best) & 85 & SSIEN (2016) \\
\hline SSIH & Sustainable Society Index - Human Wellbeing & 1-10 (Best) & 85 & SSIH (2016) \\
\hline WGI & World Giving Index & 0-100 (Best) & 58 & CAF (2013) \\
\hline WRI & World Risk Index & (Best) 0.36-50.28 & 93 & BEH (2018) \\
\hline
\end{tabular}

Notes: $\mathrm{BEH}=$ Bundnis Entwicklung Hilft, CIESIN = Center for International Earth Science Information Network, CAF $=$ Charities Aid Foundation, EIU = Economist Intelligence Unit, GFN = Global Footprint Network, HPI = Happy Planet Index, IEP = Institute of Economic \& Peace, $\mathrm{HF}=$ Heritage Foundation, $\mathrm{LI}=$ Legatum Institute, NDAll = Notre Dame Adaption Initiative Index, Ow = Our World, REVI = Retrospective Economic Vulnerability Index, SCF = Save the Children Fund, SDAC = Socioeconomic Data and Applications Center, SPI = Social Progress Imperative, SDGI = Sustainable Development Goals Index, SSIEC = Sustainable Society Index - Economic Wellbeing, SSIEN = Sustainable Society Index - Environmental Wellbeing, SSIH = Sustainable Society Index - Human Wellbeing, WB = the World Bank, TI, Transparency International, UNDP = United Nation Development Programme, UNDP = United Nations Development Programme, WEF = World Economic Forum 


\subsubsection{Data Preparation}

Before analysis could be conducted on the collected sustainability indices, the data needed to be cleaned and prepared. By maintaining quality assurance for the countries and indices chosen, they must meet at least a threshold of $50 \%$ within the database. This means that for an index to be included in the analysis, it must contain values for the majority of the countries in the study area. For this reason, Somalia 1 of the 54 countries of Africa was excluded from the study, with only $45 \%$ of indices completed. One of the 31 collected indices initially, Global Information Networking Institute Coefficient (GINI Index) was excluded since it represented only $23 \%$ of the study area.

More than three-quarters of the indices that were collected contained missing values, as seen in table 1. To fill in the null values that were found in the index, a multiple imputation procedure was conducted on the 53 countries. The statistical software used for the multiple imputation procedure was SPSS (version 18, IBM,2009). The 30 indices went through a linear multiple regression model that imputed the null values within the database with five estimated values from the most to the least completed indices (Appendix A). The median of the five estimated values was used to replace the original null value from the database. It should be acknowledged that by taking the median of the five estimated values runs the risk of losing potential countries with outlier scores. With all the null values replaced the indices went under a descriptive statistic frequencies analysis to evaluate the Gaussian distribution to determine where data transformations were needed.

Data transformation was conducted on the 30 indices included in the analysis as needed to improve the normal distribution. Thus, to normalize the data, two equations were used depending on whether the index was proportional or not. Values that contain proportional data such as percentages used the following arc - sin formula (Neal, Ehlinger, \& Shaker, 2007, p. 59):

\section{Normalized Value $=$ ASN $(S Q R($ Parameter $/ 100)$}

For values that contain non-proportional data such as straight values, logarithm equation was used (Neal, Ehlinger, \& Shaker, 2007, p. 59):

$$
\text { Normalized Value }=\log (\text { Parameter }+1)
$$


The outcomes of the transformation conducted before and after normalization can be found in Appendix (B). With data preparations and cleaning completed; the database is ready for the analysis.

\subsection{Methods}

There were two main methods used for the analysis. First was a multivariate factor analysis so that the thirty indices could be reduced to six factors to aid in seeing the underlying sustainable development dimensions. The second was univariate analysis to determine if there were spatial autocorrelation from the results. To complete this, Global Moran's I, and Local Anselin Moran's I Local Indicators of Spatial Association (L.I.S.A.) statistics were used.

\subsubsection{Factor Analysis - Revealing Underlying Sustainability Dimensions}

Factor analysis (FA) was conducted on the 30 indices to reveal the underlying sustainable development dimensions of the 53 African countries. FA is mainly known for the analysis of its principal components (PCA), which summarizes many variables into a smaller, more significant variable. FA can group similar variables so that the interpretation of the data can be more comprehensive. FA, unlike regression analysis, wants high levels of multicollinearity so that clustering of the indices into factors can occur. The FA was conducted with the statistical software JMP (ver. 14.3., SAS, 2018) using PCA with prior communality (diagonals $=1$ ) and varimax rotation set to maximize the variance of the factors. Eigenvalues were assessed to determine significant factors. The standard rule is any eigenvalues more than or equal to 1 would be considered to have a significant amount of variation (Shaker, 2015). Significant factors can be located in the scree plot graph as the cut-off point displayed in Appendix (C). Thus, when deciding where indices fall within factor loading; the highest values evaluated was assigned to the coincide axis. The naming of factors was mainly based on the three highest variances within a factor; however, the other grouped indices were considered for the naming process as well.

\subsubsection{Global and Local Moran's I Statistic - Assessing Spatial Autocorrelation}

One of the common methods for determining spatial autocorrelation used to assess the resulted FA scores is the Global Moran's I statistic. Global Moran's I statistic values range from 
+1 (perfect correlation), -1 (perfect dispersion) and 0 (random spatial pattern) (Melecky, 2015). The outputs from the analysis also produce the $z$ score and $p$-value of the results on a tabular format, which can be seen in Table 2 on page 11.

Where Global Moran's I statistic looks at the spatial association of the whole study area. The Local Anselin Moran's I L.I.S.A. statistics looks at a smaller scale. Although it is possible for both Global and Local Moran's I analyze to have the same results. The L.I.S.A. statistic can identify local values that would be considered outliers to the mean in which the Global Moran's I statistic would overlook (Anselin, 1995). The L.I.S.A statistic fulfills two requirements, first be able to give the extent of significant clustering of similar values around observations. Second, the sum of all L.I.S.A. observations is proportional to the Global Moran's I (Anselin, 1995). L.I.S.A. statistics is beneficial for areas that Global Moran's I statistic has located spatial autocorrelation. L.I.S.A. statistic deconstructs the results from a global level to a local level to obtain more information about the regions. Information such as the factors high and low for, clustering (hot and cold spots) and outliers within the study area (Anselin, 1995). The Global and Local Moran's I statistic models were measured using ESRI's ArcGIS 10.6.1 (2017) Spatial Statistics Toolbox. The countries were used as the spatial location reference when conducting the Local Moran's, I statistic. For determining the search radius for the analysis, the automatic was selected to pick the most optimal distance. The search threshold distance chosen and used for every dimension was 11,174.73 Kilometres.

\subsubsection{Visualizing the Results}

The countries of Africa shapefiles were obtained from the website Geometric Design and Modeling (GDAM, 2018) and downloaded all separately and merged within ESRI's ArcGIS 10.6.1 (2017). The results from the FA and the L.I.S.A. statistics were projected onto the created map of Africa. The planned coordinate system that was used for the projection of the map is Africa Sinusoidal. The metadata of the indices, factor naming and Global Moran's I statistic were all created into a tabular form on Microsoft Excel. 


\section{4: Results and Discussion}

\subsection{Factor Analysis Sustainable Dimension}

After the factor analysis was completed on the 30 sustainable development indices, six factors were derived. All of which had eigenvalues that were above $<1$, meaning that they were all significant. Any factors that were deemed insignificant (eigenvalues $<1$ ) were not included in the analysis. The six crucial factors explain over $75 \%$ of the variation within the dataset.

The rotated factor loading displayed values for all indices. It is essential to know that only the highest values for each index were associated with a single factor. As seen in the methodology section, naming the factors was primarily based on the indices that had the highest factor loadings. The following six factors were titled: Human Prosperity (Factor 1), Political Instability and Economic Freedom (Factor 2), Environmental Wealth (Factor 3), Socioeconomic Trade-off and Risk (Factor 4), Generosity and Environmental Trade-offs (Factor 5) and Aspiring Sustainable Development (Factor 6). The naming of factors and scores can be seen in Table 2 below and the detailed factor loading can be seen in Appendix (C).

Table 2: Loading of the 30 sustainable development indices derived from the factor analysis with (varimax rotation method). Each index was assigned to the factor with the strongest correlation. The three strongest indices are in bold type and were mainly used

\begin{tabular}{|c|c|c|c|}
\hline & Positive correlations & Negative correlations & Explained variance (\%) \\
\hline \multicolumn{4}{|l|}{ Factor 1: } \\
\hline $\begin{array}{l}\text { Political Instability \& Economic } \\
\text { Freedom } \\
\text { Factor 3: }\end{array}$ & $\begin{array}{l}\text { DI }(0.86), \text { CPI }(0.84), \text { EF }(0.80) \\
\text { LPI }(0.80)\end{array}$ & GPI $(-0.73)$ & 15.99 \\
\hline Environmental Wealth & EWI (0.79), NRPI (0.68) & $\begin{array}{l}\text { ECSI }(-0.79), \text { ENVI }(-0.46) \text {, } \\
\operatorname{ECF}(-0.42)\end{array}$ & 10.31 \\
\hline \multicolumn{4}{|l|}{ Factor 4: } \\
\hline \multicolumn{4}{|l|}{ Factor 5: } \\
\hline Generosity \& Environmental Trade-offs & WGI (0.84) & ESI $(-0.50)$ & 7.17 \\
\hline \multicolumn{4}{|l|}{ Factor 6: } \\
\hline Aspiring Sustainability & HPI (0.74), EPI (0.57), SSIEC (0.57) & & 7.06 \\
\hline
\end{tabular}

Technical notes: Factoring method = Principle components; Prior Communality = Principle components (diagonals=1). A full analysis of the factor loading, and communalities can be seen in Appendix (B). 
Factor 1 named human prosperity makes up $28.06 \%$ of the total variance and contains 11 of the 30 indices used. Most of the indices were positively correlated and highly represented social progress indicators (Table 2). Human sustainable development, human development, education index and child health index had the highest positive values (>80). The next six indices were positively correlated ( $<80$ to $>70)$, SDGI, SPI SSIH, HWI and NDGAIN. The positively associated indices for factor one all represent human sustainable development with human wellbeing, social progress and a focus on education. The strongest negative correlated indices were CDI (-0.84) and less negatively correlated SSIEN (-0.61). Libya ranked the highest for human prosperity, followed by Algeria, Tunisia and Seychelles. Niger was ranked the lowest for human prosperity, followed by Chad, Burkina Faso and Mali (Figure 2).

Factor 2 named political instability \& economic freedom explains $15.99 \%$ of the variance and encompass social instability and economic quality (Table 2). The highest positively correlated indices were democracy index, corruption perception, economic freedom and legatum prosperity $(\geq 0.80)$. The only negatively correlated index was global peace $(-0.73)$. The highest-ranked countries for factor 2 were Mauritius, followed by Cape Verde, Rwanda and Botswana being very close behind. Nations that ranked lowest in factor 2 were Libya, South Sudan, Congo and Equatorial Guinea (Figure 2).

Factor 3 named environmental wealth explain $10.31 \%$ of the variance and is characterized by the need for ecological protection (Table 2). The highest positively correlated indices were ecological wealth (0.79) and natural resource protection index (0.68). The highest negatively correlated indices were ECSI (-0.79), along with less negatively correlated ENVI (0.46) and ECF (-0.42). Countries that ranked the highest for factor 3 was Congo, Botswana, Gabon and Equatorial Guinea. The lowest ranking countries were Libya, Mauritania, Comoros and Sudan (Figure 2). 


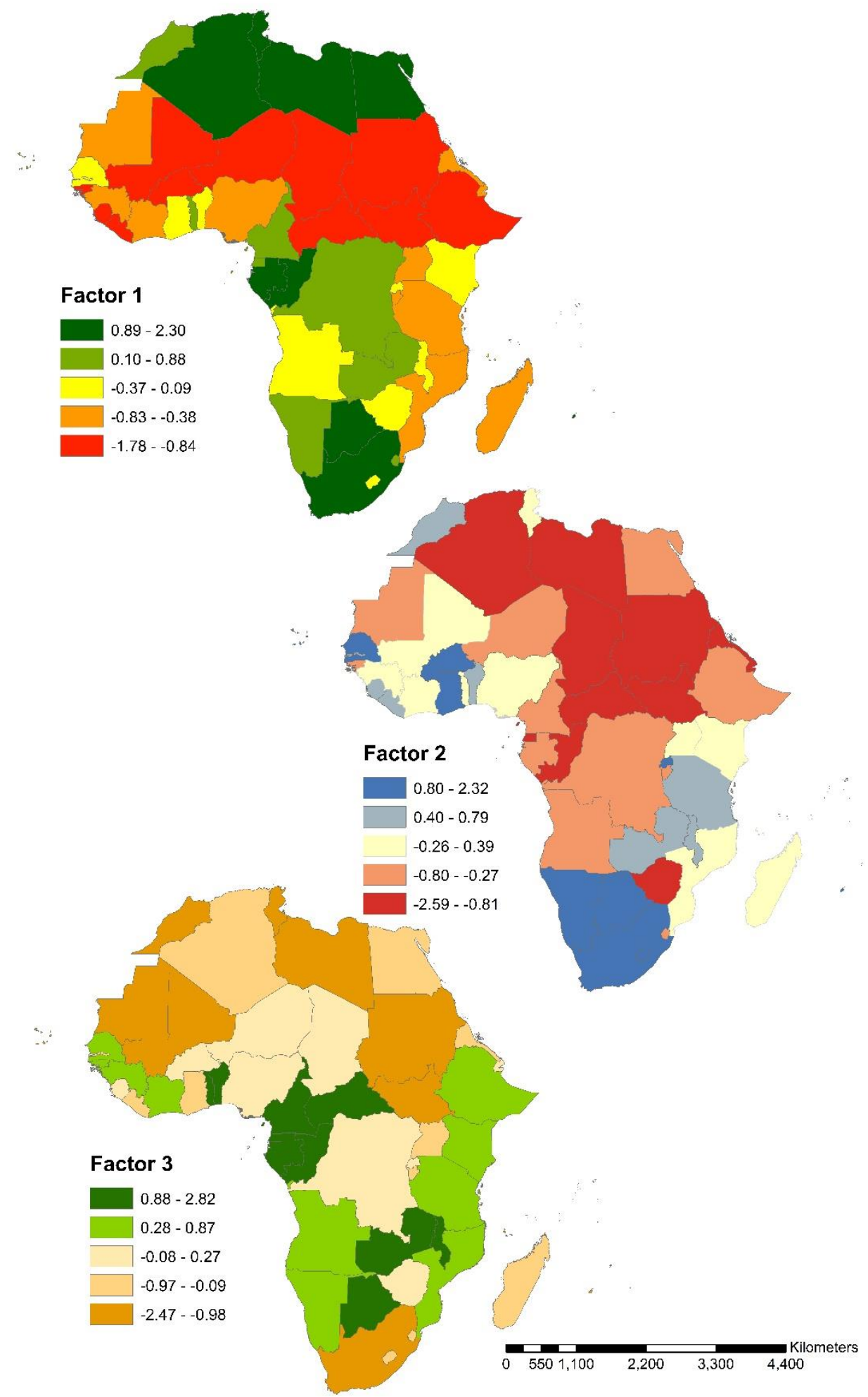

Figure 2: Spatial distribution of factors scores for the first three dimensions (Eigenvalues $>1$ ) across Africa. The dimensions are as followed F1, human prosperity; F2, political instability \& economic freedom; F3, environmental wealth. 
Factor 4 named socioeconomic vulnerabilities and risk had a variance of $8.21 \%$ and included attributes of unstable economic gain, gender inequality and risk of natural hazards (Table 2). The highest positively correlated for factor 4 were gross domestic product $(0.77)$ and world risk index (0.67). The most strongly negative correlation was the global gender gap ($0.85)$, and economic vulnerability $(-0.51)$. Countries that listed the highest for factor 4 were South Africa, Nigeria, Kenya and Egypt. The countries that were ranked the lowest were Gambia, Comoros, Seychelles and Equatorial Guinea (Figure 3).

Factor 5 named generosity and environmental trade-offs had a variance of $7.17 \%$ and only included two indices (Table 2). The world giving index was strongly positively correlated (0.84), and the economic stress index had a moderately negative correlation $(-0.50)$. Countries that ranked the highest for factor 5 were Eritrea, Equatorial Guinea, Sierra Leone and Sao Tome and Principe. The countries that ranked the lowest were Central African Republic, Mali, Seychelles and Botswana (Figure 3).

Factor 6 named aspiring sustainability had the lowest variance at 7.06 and was characterized by the attributes that account positively for the three pillars of sustainability (Table 2). The highest positively correlated indices were happy planet $(0.74)$, environmental performance (0.57) and Sustainable society economic wellbeing (0.57). The highest-ranked countries were Equatorial Guinea, Sao Tome and Principe, Morocco and Algeria. The lowestranked countries were as follows Lesotho, Democratic Republic of the Congo, Congo, South Africa and Togo (Figure 3). 


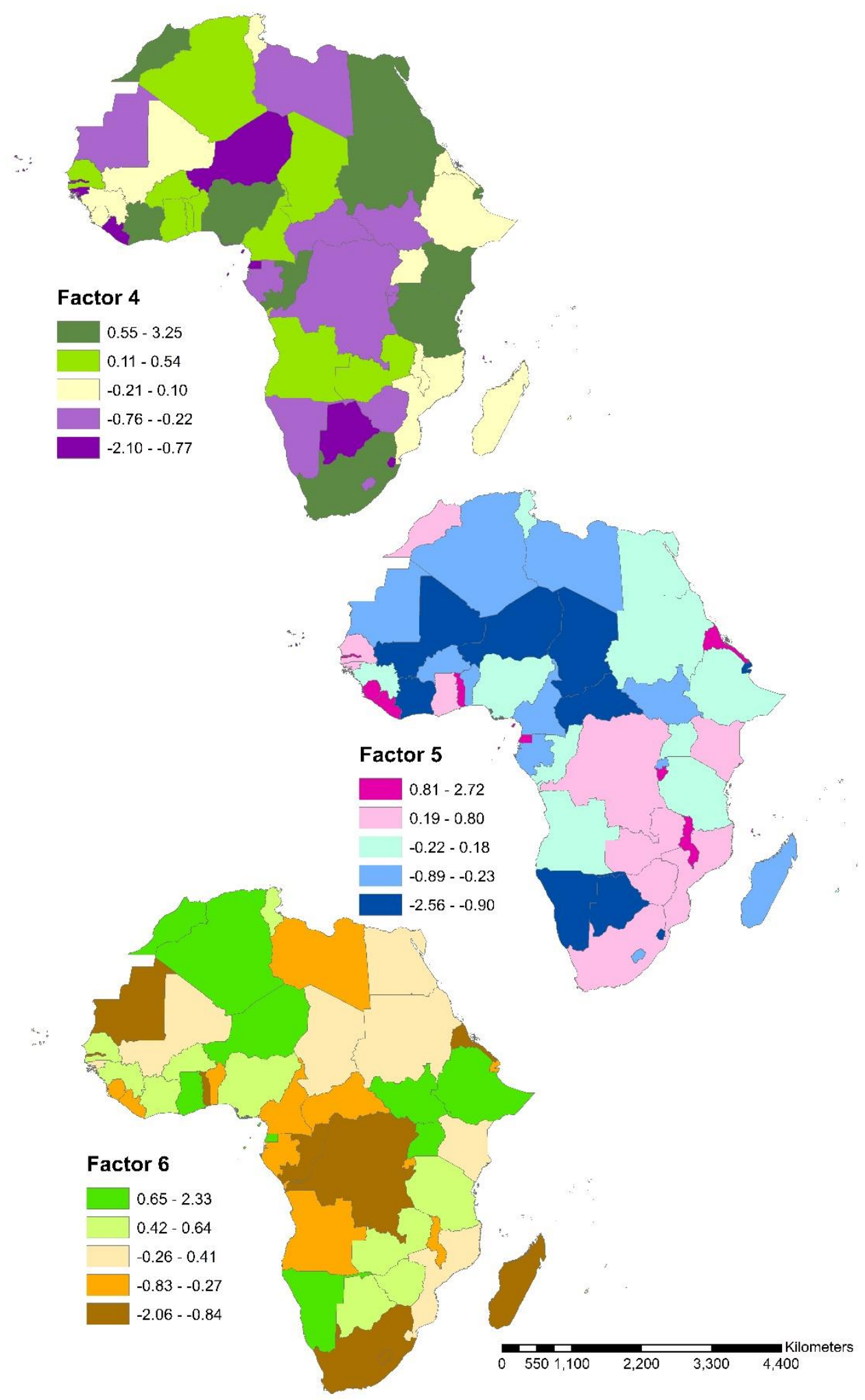

Figure 3: Spatial distribution of factors scores for the last three dimensions (Eigenvalues $>1$ ) across Africa. The dimensions are as followed F4, socioeconomic trade-offs \& risk; F5, generosity \& environmental trade-offs; F6, aspiring sustainability. 


\subsection{Dimensional Patterns of Africa}

When assessing the 53 African countries, Global Moran's analysis resulted in a degree of spatial autocorrelation among the factor dimensions. Three of the six sustainable aspects had significant levels of spatial autocorrelation (Table 3). Factor 1 had a distribution that was $<1 \%$ likelihood their clustered patterns were the result of random chance. Factors 2 and 3 also had were significant with both having $<5 \%$ chance their clustered patterns were random. The rest of the factors (4, 5 and 6$)$ had no statistical significance for the spatial patterning, thus making their distribution to be considered by random chance.

Table 3: Spatial autocorrelation results from Global Moran's I analysis for the six factor dimensions.

\begin{tabular}{lrrr}
\hline & Global Moran's I & Z-score & P-value \\
\hline Factor 1: Human Prosperity & 0.357 & $3.851^{* *}$ & $<0.001$ \\
Factor 2: Political Instability \& Economic Freedom & 0.202 & $2.271^{*}$ & 0.023 \\
Factor 3: Environmental Wealth & 0.217 & $2.425^{*}$ & 0.015 \\
Factor 4: Socioeconomic Vulnerabilities \& Risk & -0.016 & $0.038-$ & 0.970 \\
Factor 5: Generosity \& Environmental Trade-offs & 0.111 & $1.345-$ & 0.179 \\
Factor 6: Aspiring Sustainable Development & 0.038 & $0.584-$ & 0.559 \\
\hline
\end{tabular}

- Denotes random spatial pattern. * Denotes $<5 \%$ chance random pattern.

** Denotes $<1 \%$ Chance random pattern.

The L.I.S.A index, Anselin Moran's I, measured and visualized the local clustering of the six sustainable development dimensions. The human prosperity (factor 1 ) had high levels of grouping within the mid-western and northern lands of Africa, specifically the country of Tunisia, Libya, Algeria, Morocco, Gabon and Congo. Low levels of clustering occurred through the mid-northern areas of Africa, encompassing Niger, Chad, Central African Republic, Mauritania, Guinea, Sierra Leone, Liberia, Cote D' Ivoire, South Sudan and Kenya. There were no countries that resulted in the significant statistic of high or low outliers for human prosperity (Figure 4).

Political instability \& economic freedom (factor 2 ) had significantly high levels of clustering for Cote $D^{\prime}$ Ivoire and Benin on the central-western side of Africa. Low levels of clustering occurred in the central and northeast of Africa, containing Gabon, Central African 
Republic, Cameroon, Sudan, Ethiopia, Eritrea and Egypt. The high-level outliers were in Burundi, and low-level outliers were in Tunisia (Figure 4).

Environmental wealth (factor 3 ) had high levels of clustering in western and southern portions of Africa. Countries located in these areas were Equatorial Guinea, Sao Tom and Principe, Congo, Gabon, Cameroon, Zimbabwe and Zambia. Low levels of clustering occurred in Madagascar, Egypt and Tunisia. There were no high-level outliers, and the only low-level outliers country was Seychelles located on the southeastern islands of Africa (Figure 4). 


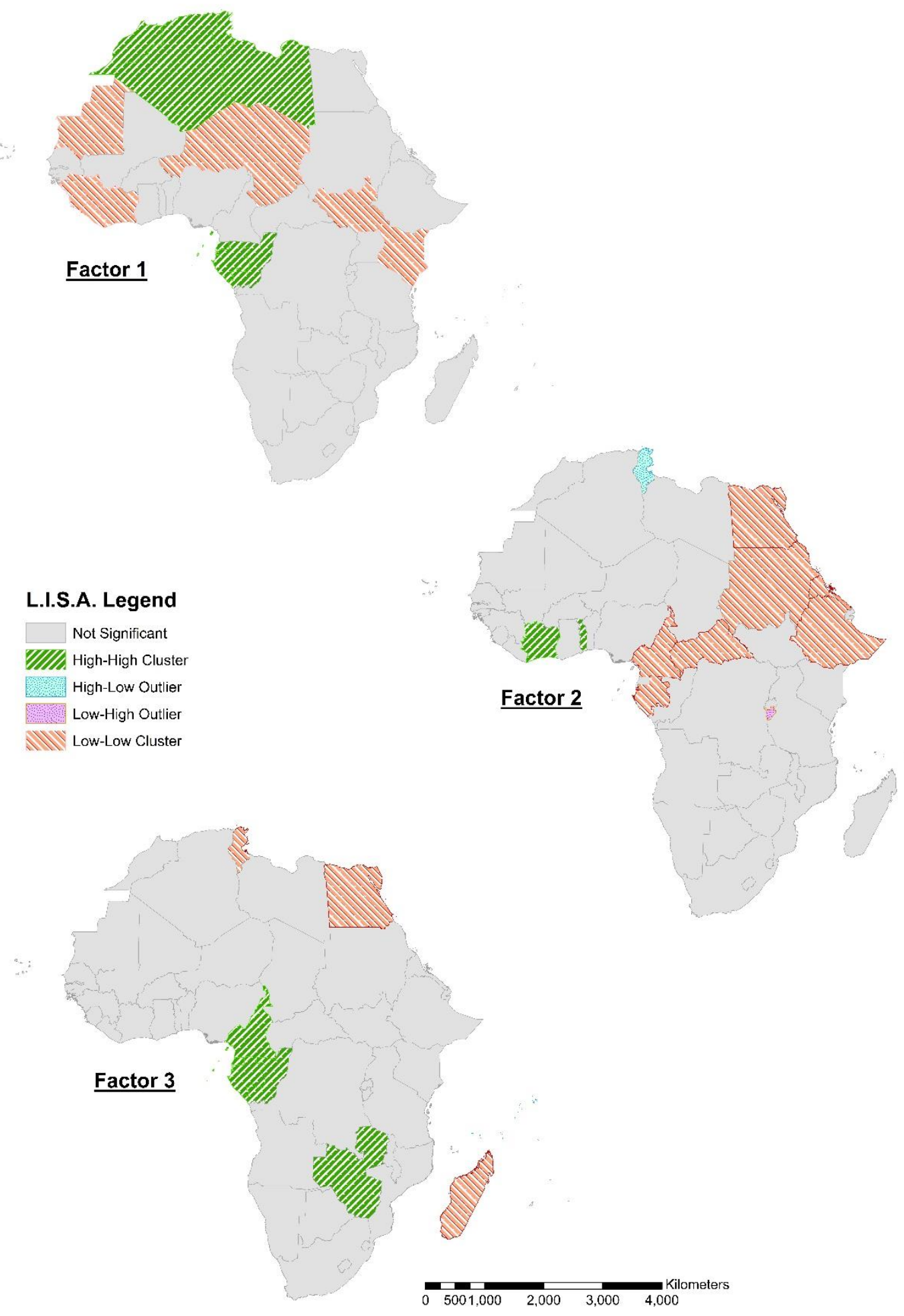

Figure 4: Local Anselin Moran's I index of spatial association displaying clustering of the six factors across Africa. The factors are as followed, F1, human prosperity; F2, political instability \& economic freedom; F3, environmental wealth. 
Socioeconomic vulnerability and risk (factor 4) had no high-level clustering. However, low-level clusters occurred in the northwestern and southeastern coast of Africa, including Cape Verde, Guinea-Bissau and Seychelles. High-level outliers were in Niger, and low-level outliers were located in Senegal (Figure 5).

Generosity and environmental trade-offs (factor 5) had no high-level clustering, although Chad was the only country to have low-level clustering. High-level outliers only occurred in Guinea and Gabon with no low-level outliers occurring in Africa (Figure 5).

Aspiring sustainable development (factor 6) had high-level clustering in Algeria. Lowlevelling clustering occurred in the Democratic Republic of the Congo and Mozambique. No high or low-level outliers occurring in Africa for aspiring sustainable development (Figure 6). 


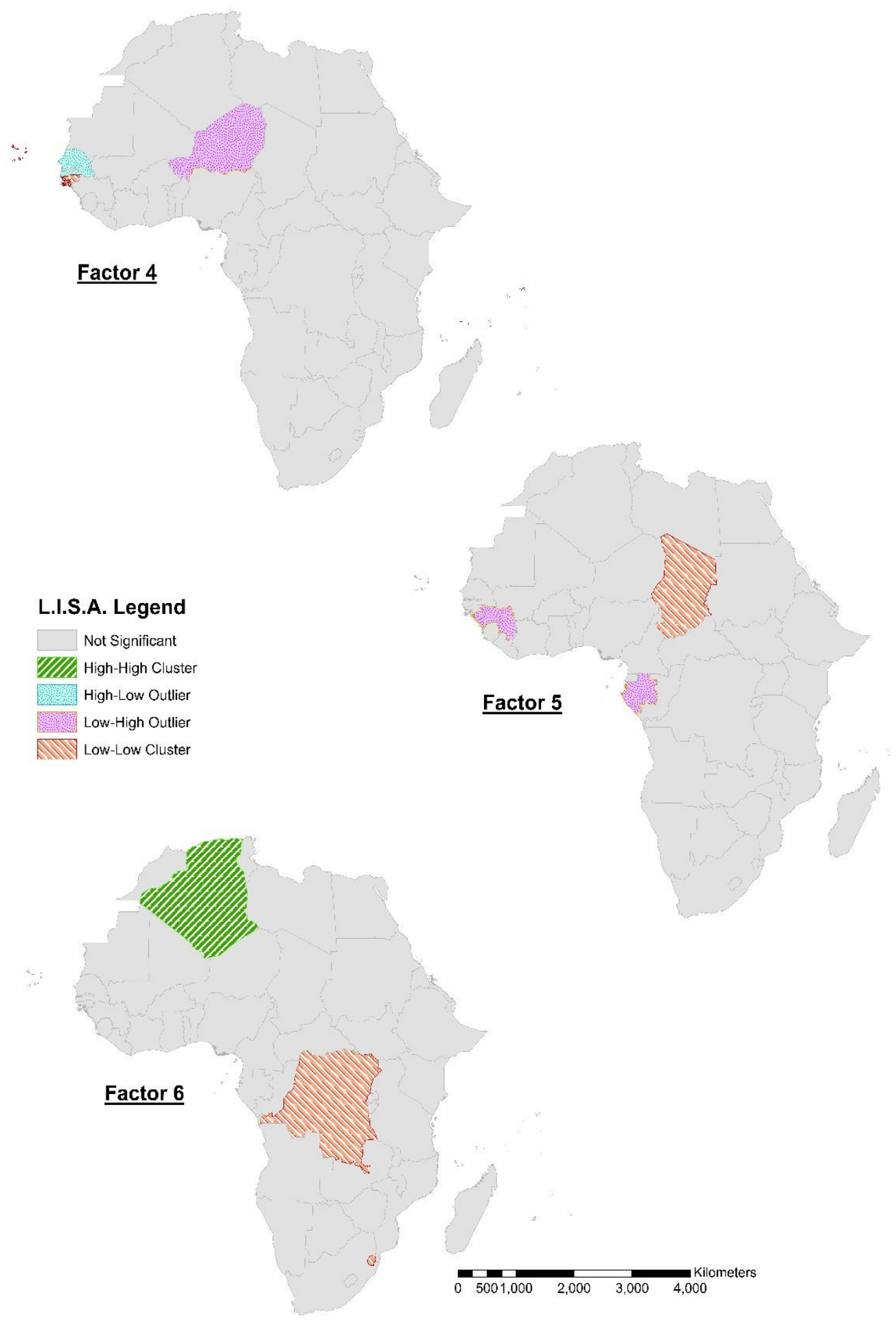

Figure 5: Local Anselin Morans's I index of spatial association displaying clustering of the six factors across Africa. The factors are as followed, F4, socioeconomic vulnerabilities \& risk; F5, generosity \& environmental trade-offs; F6, aspiring sustainability. 


\subsection{Discussion}

The multivariant factor analysis conducted on the collection of 30 sustainability indices across 53 countries of Africa, revealed important information and visualization of the condensed indices. The factor analysis discovered six significant dimensions of sustainable development. Thus, answering the first research objective of the paper, that there were underlying sustainable development dimensions from a collection of sustainability indices in Africa.

Deriving from the results of the factor analysis, indices that scored the highest per dimension were only associated with them. By doing this, a better understanding of their themes was obtained (Table 2). The grouped factors revealed that there were high levels of redundancy within the collected indices, which means that a handful of indices could describe the sustainable development of Africa. These results coincide with past studies completed with the same analysis for Asia and America (Shaker, 2015, 2018). High levels of redundancies were found on a national level with a collection of sustainable development indices.

Factors 1 and 2 alone contained 11 and 5 indices and accounted for over $57 \%$ of the factors explained variance ( $44 \%$ of total variance). Both sustainable dimensions had underlying themes that solely focus on the social and economic aspect of the three pillars of sustainability.

Human prosperity (factor 1 ) displaying countries that are associated with or disassociated with positive human development and minimal economic drawbacks. Political Instability \& Economic Freedom (factor 2) displayed countries that are or are not associated with democracy, viewed corruption, economic freedom and unpeaceful. Both factors contained no indices that reflect on the environmental pillar of sustainability. The results suggest that the overall focus of the collected indices was from an anthropocentric standpoint. It is demonstrating that the areas that are most prominent for the three pillars of sustainability from the collection of indices were the social and economic pillars. Thus, answering the second research question from the paper. Similar results were achieved by Shaker $(2015,2018)$ with the sustainability indices biasing towards the anthropocentric aspects of sustainable development. 
Factor 3 dimension showed a high need for environmental wealth with a total variance of $10.31 \%$. The countries that scored highly have a high correlation with ecological wealth, with a large proportion of the natural resources under protection. High levels of natural resource protection could be due to countries that are highly reliant on resource extraction for their economy. This rings true for highly scored countries; Congo is scoring the highest in the factor is Africa's largest petroleum producer. Botswana receiving the second-highest score economy is a large exporter of beef and is the third-largest producer of diamonds in the world (Worldatlas, 2016). The low scoring countries are ones without as much ecological wealth or resource extraction focus for their economy. The lowest country that scored in this factor was Algeria. This country scored so poorly since the majority of the country surface area is covered by the Sahara Desert, greatly limiting their ecological wealth.

Factor 4 contained $8.21 \%$ of the total variance and included vulnerable aspects of all three pillars of sustainability. Countries that are positively correlated have large economies that are vulnerable as well as poor gender equality with the element of natural hazards occurring.

Factor 5 named generosity and environmental trade-offs had an explained variance of $7.17 \%$ and only contained two indices. Interesting enough countries that scored high in this dimension were highly charitable to places around the world but had poor environmental sustainability.

Factor 6 had an explained variance of $7.06 \%$ and was named aspiring sustainability. Even though this was the lowest explained variance, it contained three indices that each can be derived from one of the three pillars of sustainability positively. Countries that were scored highly for factor 6 showed aspiring sustainable development by having positive levels for the wellbeing of all, environmentally conscious and economic wellbeing.4

To determine if the results from the mapped factor analysis showed any spatial autocorrelation, they were put through a Global Moran's I analysis. The results determined there was a reason to believe that there was positive spatial autocorrelation among three of the six dimensions. The first three factors had the highest probability that spatial autocorrelation had occurred. Thus, answering the final research objective since there was 
spatial autocorrelation between the underlying sustainable development themes. Factor 1 had the highest spatial autocorrelations with $<1 \%$ chance clustering was due to random chance. Factor 2 and 3 both had spatial autocorrelation with $<5 \%$ chance clustering was due to random chance.

Local Anselin Moran's I L.I.S.A statistic was used to deconstruct patterns by understanding where specifically the clustering and outliers were located. Considering factor 1 (human prosperity), which is highly correlated with human sustainable development, the majority of the high clustering observations occurred in North Africa. On the other hand, any low-level human prosperity scores were all located within (SSA). The divide depicted in factor 1 is interesting since SSA, as stated above, has one of the highest malnourished populations in the world and resulted in low clustering of human development indices (Schlenker, W., \& Lobell, B., 2010). 


\section{5: Limitation and Conclusion}

\subsection{Limitations}

One of the most significant limitations when doing the analysis was data availability. Since the whole analysis relies on an agglomeration of indices collected by other institutes, leads to potentially unreliable results. Results derived from the study were highly reliant on the quality of data collected. Data that has missing values or in need of data transformations can change the reliability of the findings. Steps like multiple imputations used to fill null values are useful; however, having a complete data set would be better. Due to an insignificant amount, $(<50 \%)$ of data on one country, Somalia and one index GINI had to be excluded from the study. Another aspect for data availability is the timeline the indices were taken. The majority of indices were obtained from 2016 or higher, 10 of the 30 indices used were lower than in 2016. Ideally having data that is complete and all span across the most recent year would be able to make the most accurate results. The other limitation was time, similar to data availability, the more time allotted to complete a study would result in having more indices included. With more high-quality indices acquired, the better interpretations can be made from the results.

\subsection{Conclusion}

The paper summarized 30 sustainability indices with a multivariant factor analysis that revealed six sustainable development dimensions. The factors discovered were human prosperity (factor 1), political instability and economic freedom (factor 2), environmental wealth (factor 3), socioeconomic vulnerability and risk (factor 4), generosity and environmental trade-offs (factor 5) and aspiring sustainable development (factor 6). Global Moran's I was used to assess spatial autocorrelation within the study area. The spatial statistics obtained stated that three of the six factors had a significant probability that their patterns were not due to random chance. To deconstruct the results Local Moran's I L.I.S.A. analysis was used to display the outliers and clustering from the factors across Africa. The research objectives were accomplished throughout the paper. The first objective was, is there underlying sustainability dimension within a collection of sustainability indices. The factor analysis conducted proved that there were six significant sustainability dimensions within the selection of indices. The 
second research objective was, of the three pillars of sustainability which areas will be most prominent within a collection of sustainability indices. Since factor 1 and 2 had an explained variance of over $54 \%$ and were made up from socioeconomic indices, it can be said that the social and economic pillars of sustainability were more prominent. The final research objective answered was will there be spatial autocorrelation between the underlying sustainable development dimensions. The results from the Global Moran's I conducted determined that three dimensions had a significantly small probability of being clustered by random chance.

This study had significant findings for the 30 sustainability indices over 53 countries of Africa. By uncovering the six dimensions of sustainable development, this paper has been able to show a perceived divide in human development from northern Africa and SSA from the mapped factor 1 (Figure 1, 4). Also, shed light on areas that good resource extraction environmental practices should be implemented to provide a more sustainable future. This paper will be used to help fill the gap in the few reductionist approaches that has been conducted. Ensuring for a better understanding of Africa's spatial distribution of development and underlying sustainability correlations. Research conducted here should not be considered as a final analysis on Africa but a stepping stone to be improved upon and updated for sustainable development studies to come. 


\section{Appendix A}

Multiple Imputation Model Conducted in SPSS

*Impute Missing Data Values.

DATASET DECLARE ImputeMissingData_Correct.

DATASET DECLARE IterationHistoryMissingData.

MULTIPLE IMPUTATION CDI_2010 CHI_2015 CPI_2016 DI_2018 ECF_2016 ECSI_2001 ECVI_2013

EF_2019 El_2013 ENVI_2004 EPI_2018 ESI_2005 EWI_2001 GDP_20162017 GGG_2018 GPI_2019

HDI_2017 HPI_2016 HSDI_2010 HWI_2001 LPI_2018 NDGAIN_2017 NRPI_2017 SDGI_2018 SPI_2018

SSIEC_2016 SSIEN_2016 SSIH_2016 WGI_2013 WRI_2018

/IMPUTE METHOD=AUTO NIMPUTATIONS=5 MAXPCTMISSING=NONE

/MISSINGSUMMARIES NONE

/IMPUTATIONSUMMARIES MODELS DESCRIPTIVES

/OUTFILE IMPUTATIONS=ImputeMissingData_Correct FCSITERATIONS=IterationHistoryMissingData . 


\section{Multiple Imputation}

Notes

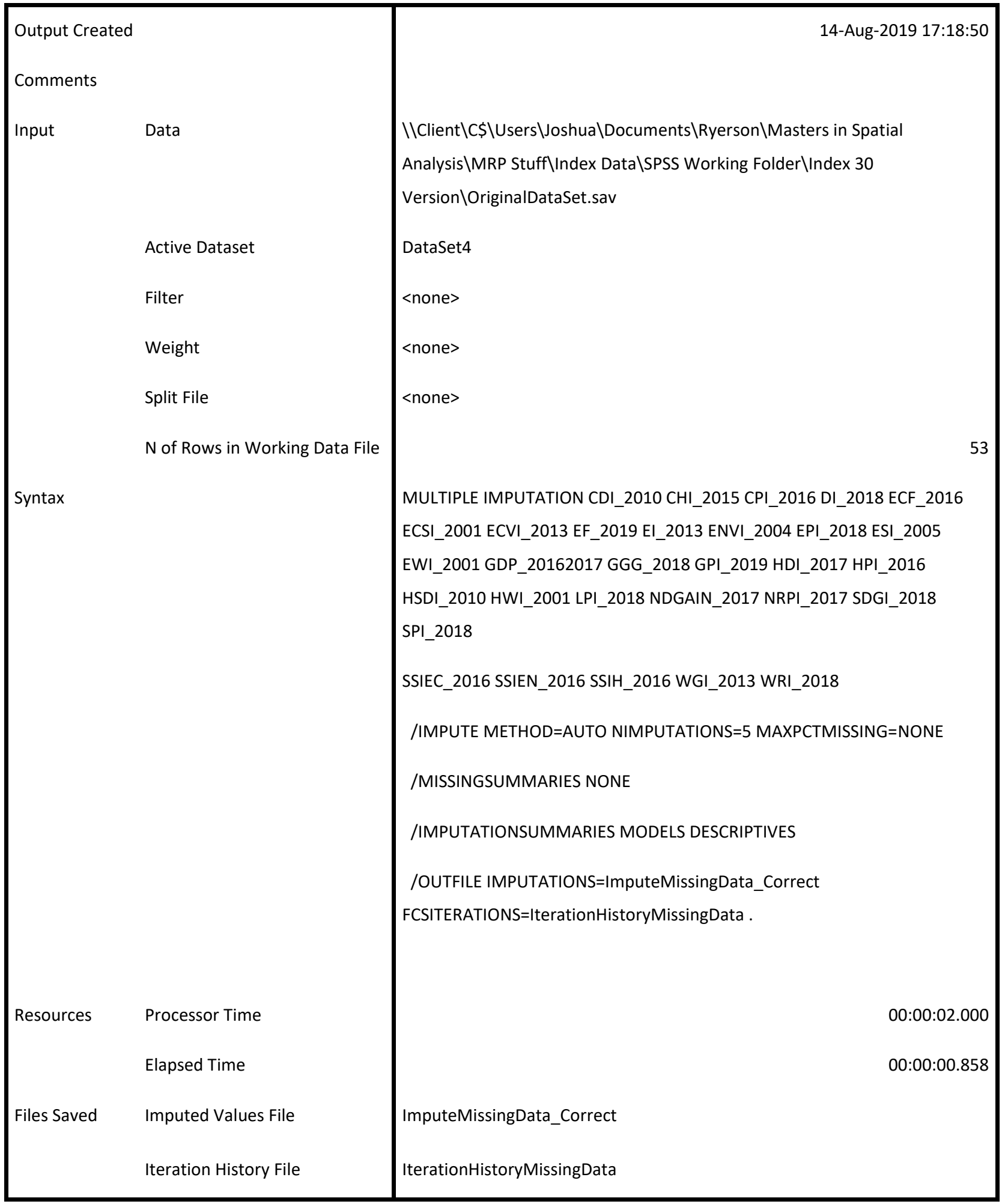


Imputation Specifications

\begin{tabular}{|l|lr|}
\hline Imputation Method & Automatic & \\
Number of Imputations & Linear Regression & \\
Interactions Included in & (none) & \\
Models & & $100.0 \%$ \\
Maximum Percentage of & & \\
Missing Values & & \\
Maximum Number of & & \\
Parameters in Imputation & & \\
Model & & \\
\hline
\end{tabular}


Imputation Results

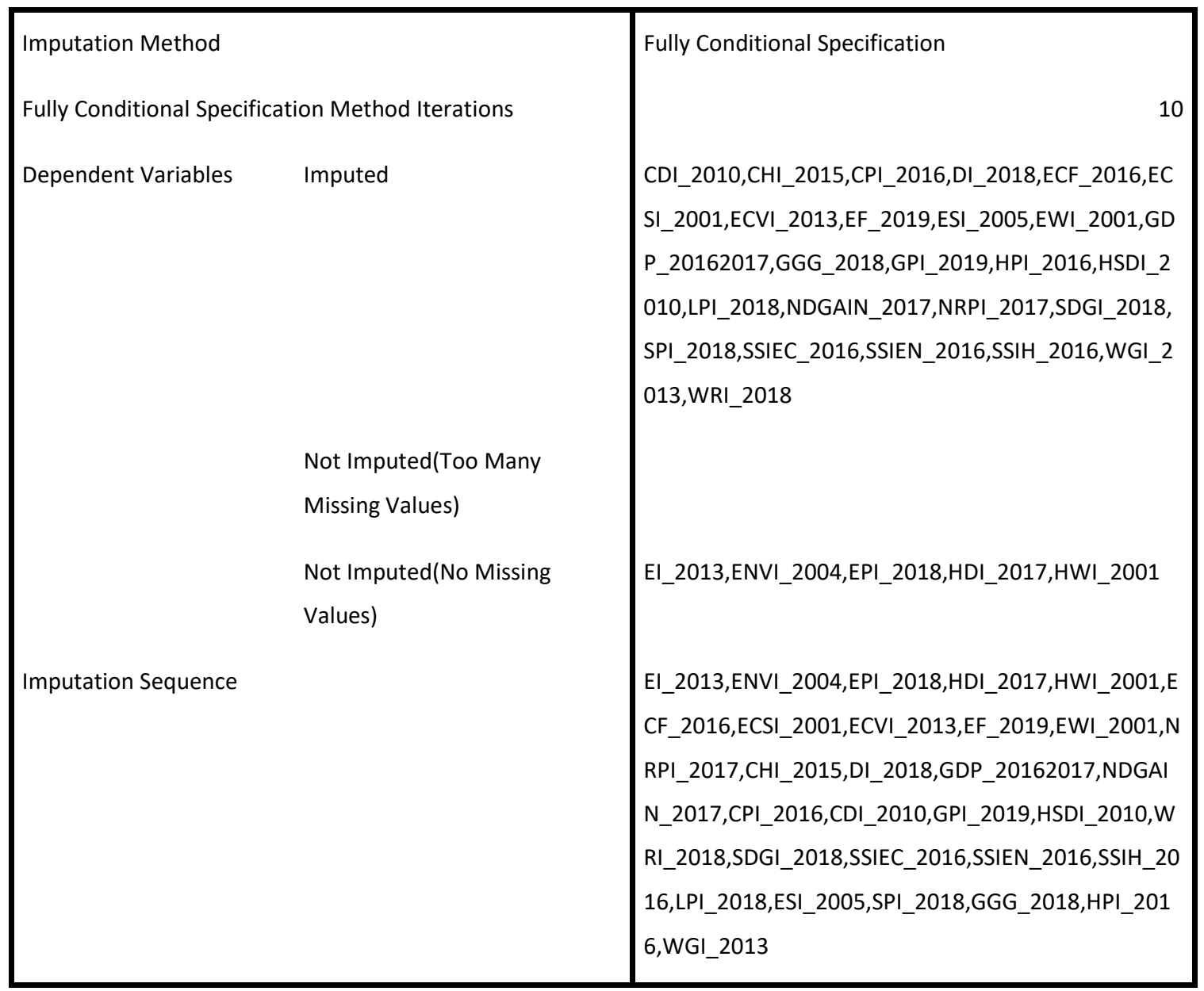


Imputation Models

\begin{tabular}{|c|c|c|c|c|}
\hline & \multicolumn{2}{|r|}{ Model } & \multirow{2}{*}{$\begin{array}{l}\text { Missing } \\
\text { Values }\end{array}$} & \multirow{2}{*}{$\begin{array}{l}\text { Imputed } \\
\text { Values }\end{array}$} \\
\hline & Type & Effects & & \\
\hline ECF_2016 & $\begin{array}{l}\text { Linear } \\
\text { Regression }\end{array}$ & $\begin{array}{l}\text { EI_2013,ENVI_2004,EPI_2018,HDI_2017,HWI_2001,ECSI_2001,ECVI_ } \\
\text { 2013,EF_2019,EWI_2001,NRPI_2017,CHI_2015,DI_2018,GDP_20162 } \\
\text { 017,NDGAIN_2017,CPI_2016,CDI_2010,GPI_2019,HSDI_2010,WRI_2 } \\
\text { 018,SDGI_2018,SSIEC_2016,SSIEN_2016,SSIH_2016,LPI_2018,ESI_20 } \\
\text { 05,SPI_2018,GGG_2018,HPI_2016,WGI_2013 }\end{array}$ & 1 & 5 \\
\hline ECSI_2001 & $\begin{array}{l}\text { Linear } \\
\text { Regression }\end{array}$ & $\begin{array}{l}\text { EI_2013,ENVI_2004,EPI_2018,HDI_2017,HWI_2001,ECF_2016,ECVI_2 } \\
\text { 013,EF_2019,EWI_2001,NRPI_2017,CHI_2015,DI_2018,GDP_201620 } \\
\text { 17,NDGAIN_2017,CPI_2016,CDI_2010,GPI_2019,HSDI_2010,WRI_20 } \\
\text { 18,SDGI_2018,SSIEC_2016,SSIEN_2016,SSIH_2016,LPI_2018,ESI_200 } \\
\text { 5,SPI_2018,GGG_2018,HPI_2016,WGI_2013 }\end{array}$ & 1 & 5 \\
\hline ECVI_2013 & $\begin{array}{l}\text { Linear } \\
\text { Regression }\end{array}$ & $\begin{array}{l}\text { EI_2013,ENVI_2004,EPI_2018,HDI_2017,HWI_2001,ECF_2016,ECSI_2 } \\
\text { 001,EF_2019,EWI_2001,NRPI_2017,CHI_2015,DI_2018,GDP_201620 } \\
\text { 17,NDGAIN_2017,CPI_2016,CDI_2010,GPI_2019,HSDI_2010,WRI_20 } \\
\text { 18,SDGI_2018,SSIEC_2016,SSIEN_2016,SSIH_2016,LPI_2018,ESI_200 } \\
\text { 5,SPI_2018,GGG_2018,HPI_2016,WGI_2013 }\end{array}$ & 1 & 5 \\
\hline EF_2019 & $\begin{array}{l}\text { Linear } \\
\text { Regression }\end{array}$ & $\begin{array}{l}\text { EI_2013,ENVI_2004,EPI_2018,HDI_2017,HWI_2001,ECF_2016,ECSI_2 } \\
\text { 001,ECVI_2013,EWI_2001,NRPI_2017,CHI_2015,DI_2018,GDP_20162 } \\
\text { 017,NDGAIN_2017,CPI_2016,CDI_2010,GPI_2019,HSDI_2010,WRI_2 } \\
\text { 018,SDGI_2018,SSIEC_2016,SSIEN_2016,SSIH_2016,LPI_2018,ESI_20 } \\
\text { 05,SPI_2018,GGG_2018,HPI_2016,WGI_2013 }\end{array}$ & 1 & 5 \\
\hline EWI_2001 & $\begin{array}{l}\text { Linear } \\
\text { Regression }\end{array}$ & $\begin{array}{l}\text { EI_2013,ENVI_2004,EPI_2018,HDI_2017,HWI_2001,ECF_2016,ECSI_2 } \\
\text { 001,ECVI_2013,EF_2019,NRPI_2017,CHI_2015,DI_2018,GDP_201620 } \\
\text { 17,NDGAIN_2017,CPI_2016,CDI_2010,GPI_2019,HSDI_2010,WRI_20 } \\
\text { 18,SDGI_2018,SSIEC_2016,SSIEN_2016,SSIH_2016,LPI_2018,ESI_200 } \\
\text { 5,SPI_2018,GGG_2018,HPI_2016,WGI_2013 }\end{array}$ & 1 & 5 \\
\hline NRPI_2017 & $\begin{array}{l}\text { Linear } \\
\text { Regression }\end{array}$ & $\begin{array}{l}\text { EI_2013,ENVI_2004,EPI_2018,HDI_2017,HWI_2001,ECF_2016,ECSI_2 } \\
\text { 001,ECVI_2013,EF_2019,EWI_2001,CHI_2015,DI_2018,GDP_2016201 } \\
\text { 7,NDGAIN_2017,CPI_2016,CDI_2010,GPI_2019,HSDI_2010,WRI_201 } \\
\text { 8,SDGI_2018,SSIEC_2016,SSIEN_2016,SSIH_2016,LPI_2018,ESI_2005, } \\
\text { SPI_2018,GGG_2018,HPI_2016,WGI_2013 }\end{array}$ & 1 & 5 \\
\hline
\end{tabular}




\begin{tabular}{|c|c|c|c|c|}
\hline CHI_2015 & $\begin{array}{l}\text { Linear } \\
\text { Regression }\end{array}$ & $\begin{array}{l}\text { EI_2013,ENVI_2004,EPI_2018,HDI_2017,HWI_2001,ECF_2016,ECSI_2 } \\
\text { 001,ECVI_2013,EF_2019,EWI_2001,NRPI_2017,DI_2018,GDP_201620 } \\
\text { 17,NDGAIN_2017,CPI_2016,CDI_2010,GPI_2019,HSDI_2010,WRI_20 } \\
\text { 18,SDGI_2018,SSIEC_2016,SSIEN_2016,SSIH_2016,LPI_2018,ESI_200 } \\
\text { 5,SPI_2018,GGG_2018,HPI_2016,WGI_2013 }\end{array}$ & 2 & 10 \\
\hline DI_2018 & $\begin{array}{l}\text { Linear } \\
\text { Regression }\end{array}$ & $\begin{array}{l}\text { EI_2013,ENVI_2004,EPI_2018,HDI_2017,HWI_2001,ECF_2016,ECSI_2 } \\
\text { 001,ECVI_2013,EF_2019,EWI_2001,NRPI_2017,CHI_2015,GDP_2016 } \\
\text { 2017,NDGAIN_2017,CPI_2016,CDI_2010,GPI_2019,HSDI_2010,WRI_ } \\
\text { 2018,SDGI_2018,SSIEC_2016,SSIEN_2016,SSIH_2016,LPI_2018,ESI_2 } \\
\text { 005,SPI_2018,GGG_2018,HPI_2016,WGI_2013 }\end{array}$ & 2 & 10 \\
\hline $\begin{array}{l}\text { GDP_2016- } \\
2017\end{array}$ & $\begin{array}{l}\text { Linear } \\
\text { Regression }\end{array}$ & $\begin{array}{l}\text { EI_2013,ENVI_2004,EPI_2018,HDI_2017,HWI_2001,ECF_2016,ECSI_2 } \\
\text { 001,ECVI_2013,EF_2019,EWI_2001,NRPI_2017,CHI_2015,DI_2018,N } \\
\text { DGAIN_2017,CPI_2016,CDI_2010,GPI_2019,HSDI_2010,WRI_2018,SD } \\
\text { GI_2018,SSIEC_2016,SSIEN_2016,SSIH_2016,LPI_2018,ESI_2005,SPI_ } \\
\text { 2018,GGG_2018,HPI_2016,WGI_2013 }\end{array}$ & 2 & 10 \\
\hline $\begin{array}{l}\text { NDGAIN_20 } \\
17\end{array}$ & $\begin{array}{l}\text { Linear } \\
\text { Regression }\end{array}$ & $\begin{array}{l}\text { EI_2013,ENVI_2004,EPI_2018,HDI_2017,HWI_2001,ECF_2016,ECSI_2 } \\
\text { 001,ECVI_2013,EF_2019,EWI_2001,NRPI_2017,CHI_2015,DI_2018,G } \\
\text { DP_20162017,CPI_2016,CDI_2010,GPI_2019,HSDI_2010,WRI_2018,S } \\
\text { DGI_2018,SSIEC_2016,SSIEN_2016,SSIH_2016,LPI_2018,ESI_2005,SPI } \\
\text { 2018,GGG_2018,HPI_2016,WGI_2013 }\end{array}$ & 2 & 10 \\
\hline CPI_2016 & $\begin{array}{l}\text { Linear } \\
\text { Regression }\end{array}$ & $\begin{array}{l}\text { EI_2013,ENVI_2004,EPI_2018,HDI_2017,HWI_2001,ECF_2016,ECSI_2 } \\
\text { 001,ECVI_2013,EF_2019,EWI_2001,NRPI_2017,CHI_2015,DI_2018,G } \\
\text { DP_20162017,NDGAIN_2017,CDI_2010,GPI_2019,HSDI_2010,WRI_2 } \\
\text { 018,SDGI_2018,SSIEC_2016,SSIEN_2016,SSIH_2016,LPI_2018,ESI_20 } \\
\text { 05,SPI_2018,GGG_2018,HPI_2016,WGI_2013 }\end{array}$ & 3 & 15 \\
\hline CDI_2010 & $\begin{array}{l}\text { Linear } \\
\text { Regression }\end{array}$ & $\begin{array}{l}\text { EI_2013,ENVI_2004,EPI_2018,HDI_2017,HWI_2001,ECF_2016,ECSI_2 } \\
\text { 001,ECVI_2013,EF_2019,EWI_2001,NRPI_2017,CHI_2015,DI_2018,G } \\
\text { DP_20162017,NDGAIN_2017,CPI_2016,GPI_2019,HSDI_2010,WRI_2 } \\
\text { 018,SDGI_2018,SSIEC_2016,SSIEN_2016,SSIH_2016,LPI_2018,ESI_20 } \\
\text { 05,SPI_2018,GGG_2018,HPI_2016,WGI_2013 }\end{array}$ & 4 & 20 \\
\hline GPI_2019 & $\begin{array}{l}\text { Linear } \\
\text { Regression }\end{array}$ & $\begin{array}{l}\text { EI_2013,ENVI_2004,EPI_2018,HDI_2017,HWI_2001,ECF_2016,ECSI_2 } \\
\text { 001,ECVI_2013,EF_2019,EWI_2001,NRPI_2017,CHI_2015,DI_2018,G } \\
\text { DP_20162017,NDGAIN_2017,CPI_2016,CDI_2010,HSDI_2010,WRI_2 } \\
\text { 018,SDGI_2018,SSIEC_2016,SSIEN_2016,SSIH_2016,LPI_2018,ESI_20 } \\
\text { 05,SPI_2018,GGG_2018,HPI_2016,WGI_2013 }\end{array}$ & 4 & 20 \\
\hline
\end{tabular}




\begin{tabular}{|c|c|c|c|c|}
\hline HSDI_2010 & $\begin{array}{l}\text { Linear } \\
\text { Regression }\end{array}$ & $\begin{array}{l}\text { EI_2013,ENVI_2004,EPI_2018,HDI_2017,HWI_2001,ECF_2016,ECSI_2 } \\
\text { 001,ECVI_2013,EF_2019,EWI_2001,NRPI_2017,CHI_2015,DI_2018,G } \\
\text { DP_20162017,NDGAIN_2017,CPI_2016,CDI_2010,GPI_2019,WRI_201 } \\
\text { 8,SDGI_2018,SSIEC_2016,SSIEN_2016,SSIH_2016,LPI_2018,ESI_2005, } \\
\text { SPI_2018,GGG_2018,HPI_2016,WGI_2013 }\end{array}$ & 4 & 20 \\
\hline WRI_2018 & $\begin{array}{l}\text { Linear } \\
\text { Regression }\end{array}$ & $\begin{array}{l}\text { EI_2013,ENVI_2004,EPI_2018,HDI_2017,HWI_2001,ECF_2016,ECSI_2 } \\
\text { 001,ECVI_2013,EF_2019,EWI_2001,NRPI_2017,CHI_2015,DI_2018,G } \\
\text { DP_20162017,NDGAIN_2017,CPI_2016,CDI_2010,GPI_2019,HSDI_20 } \\
\text { 10,SDGI_2018,SSIEC_2016,SSIEN_2016,SSIH_2016,LPI_2018,ESI_200 } \\
\text { 5,SPI_2018,GGG_2018,HPI_2016,WGI_2013 }\end{array}$ & 4 & 20 \\
\hline SDGI_2018 & $\begin{array}{l}\text { Linear } \\
\text { Regression }\end{array}$ & $\begin{array}{l}\text { EI_2013,ENVI_2004,EPI_2018,HDI_2017,HWI_2001,ECF_2016,ECSI_2 } \\
\text { 001,ECVI_2013,EF_2019,EWI_2001,NRPI_2017,CHI_2015,DI_2018,G } \\
\text { DP_20162017,NDGAIN_2017,CPI_2016,CDI_2010,GPI_2019,HSDI_20 } \\
\text { 10,WRI_2018,SSIEC_2016,SSIEN_2016,SSIH_2016,LPI_2018,ESI_2005 } \\
\text {,SPI_2018,GGG_2018,HPI_2016,WGI_2013 }\end{array}$ & 7 & 35 \\
\hline SSIEC_2016 & $\begin{array}{l}\text { Linear } \\
\text { Regression }\end{array}$ & $\begin{array}{l}\text { EI_2013,ENVI_2004,EPI_2018,HDI_2017,HWI_2001,ECF_2016,ECSI_2 } \\
\text { 001,ECVI_2013,EF_2019,EWI_2001,NRPI_2017,CHI_2015,DI_2018,G } \\
\text { DP_20162017,NDGAIN_2017,CPI_2016,CDI_2010,GPI_2019,HSDI_20 } \\
\text { 10,WRI_2018,SDGI_2018,SSIEN_2016,SSIH_2016,LPI_2018,ESI_2005, } \\
\text { SPI_2018,GGG_2018,HPI_2016,WGI_2013 }\end{array}$ & 8 & 40 \\
\hline SSIEN_2016 & $\begin{array}{l}\text { Linear } \\
\text { Regression }\end{array}$ & $\begin{array}{l}\text { EI_2013,ENVI_2004,EPI_2018,HDI_2017,HWI_2001,ECF_2016,ECSI_2 } \\
\text { 001,ECVI_2013,EF_2019,EWI_2001,NRPI_2017,CHI_2015,DI_2018,G } \\
\text { DP_20162017,NDGAIN_2017,CPI_2016,CDI_2010,GPI_2019,HSDI_20 } \\
\text { 10,WRI_2018,SDGI_2018,SSIEC_2016,SSIH_2016,LPI_2018,ESI_2005, } \\
\text { SPI_2018,GGG_2018,HPI_2016,WGI_2013 }\end{array}$ & 8 & 40 \\
\hline SSIH_2016 & $\begin{array}{l}\text { Linear } \\
\text { Regression }\end{array}$ & $\begin{array}{l}\text { EI_2013,ENVI_2004,EPI_2018,HDI_2017,HWI_2001,ECF_2016,ECSI_2 } \\
\text { 001,ECVI_2013,EF_2019,EWI_2001,NRPI_2017,CHI_2015,DI_2018,G } \\
\text { DP_20162017,NDGAIN_2017,CPI_2016,CDI_2010,GPI_2019,HSDI_20 } \\
\text { 10,WRI_2018,SDGI_2018,SSIEC_2016,SSIEN_2016,LPI_2018,ESI_2005 } \\
\text {,SPI_2018,GGG_2018,HPI_2016,WGI_2013 }\end{array}$ & 8 & 40 \\
\hline LPI_2018 & $\begin{array}{l}\text { Linear } \\
\text { Regression }\end{array}$ & $\begin{array}{l}\text { EI_2013,ENVI_2004,EPI_2018,HDI_2017,HWI_2001,ECF_2016,ECSI_2 } \\
\text { 001,ECVI_2013,EF_2019,EWI_2001,NRPI_2017,CHI_2015,DI_2018,G } \\
\text { DP_20162017,NDGAIN_2017,CPI_2016,CDI_2010,GPI_2019,HSDI_20 } \\
\text { 10,WRI_2018,SDGI_2018,SSIEC_2016,SSIEN_2016,SSIH_2016,ESI_20 } \\
\text { 05,SPI_2018,GGG_2018,HPI_2016,WGI_2013 }\end{array}$ & 9 & 45 \\
\hline
\end{tabular}




\begin{tabular}{|c|c|c|c|c|}
\hline ESI_2005 & $\begin{array}{l}\text { Linear } \\
\text { Regression }\end{array}$ & $\begin{array}{l}\text { EI_2013,ENVI_2004,EPI_2018,HDI_2017,HWI_2001,ECF_2016,ECSI_2 } \\
\text { 001,ECVI_2013,EF_2019,EWI_2001,NRPI_2017,CHI_2015,DI_2018,G } \\
\text { DP_20162017,NDGAIN_2017,CPI_2016,CDI_2010,GPI_2019,HSDI_20 } \\
\text { 10,WRI_2018,SDGI_2018,SSIEC_2016,SSIEN_2016,SSIH_2016,LPI_20 } \\
\text { 18,SPI_2018,GGG_2018,HPI_2016,WGI_2013 }\end{array}$ & 10 & 50 \\
\hline SPI_2018 & $\begin{array}{l}\text { Linear } \\
\text { Regression }\end{array}$ & $\begin{array}{l}\text { EI_2013,ENVI_2004,EPI_2018,HDI_2017,HWI_2001,ECF_2016,ECSI_2 } \\
\text { 001,ECVI_2013,EF_2019,EWI_2001,NRPI_2017,CHI_2015,DI_2018,G } \\
\text { DP_20162017,NDGAIN_2017,CPI_2016,CDI_2010,GPI_2019,HSDI_20 } \\
\text { 10,WRI_2018,SDGI_2018,SSIEC_2016,SSIEN_2016,SSIH_2016,LPI_20 } \\
\text { 18,ESI_2005,GGG_2018,HPI_2016,WGI_2013 }\end{array}$ & 10 & 50 \\
\hline GGG_2018 & $\begin{array}{l}\text { Linear } \\
\text { Regression }\end{array}$ & $\begin{array}{l}\text { EI_2013,ENVI_2004,EPI_2018,HDI_2017,HWI_2001,ECF_2016,ECSI_2 } \\
\text { 001,ECVI_2013,EF_2019,EWI_2001,NRPI_2017,CHI_2015,DI_2018,G } \\
\text { DP_20162017,NDGAIN_2017,CPI_2016,CDI_2010,GPI_2019,HSDI_20 } \\
\text { 10,WRI_2018,SDGI_2018,SSIEC_2016,SSIEN_2016,SSIH_2016,LPI_20 } \\
\text { 18,ESI_2005,SPI_2018,HPI_2016,WGI_2013 }\end{array}$ & 16 & 80 \\
\hline HPI_2016 & $\begin{array}{l}\text { Linear } \\
\text { Regression }\end{array}$ & $\begin{array}{l}\text { EI_2013,ENVI_2004,EPI_2018,HDI_2017,HWI_2001,ECF_2016,ECSI_2 } \\
\text { 001,ECVI_2013,EF_2019,EWI_2001,NRPI_2017,CHI_2015,DI_2018,G } \\
\text { DP_20162017,NDGAIN_2017,CPI_2016,CDI_2010,GPI_2019,HSDI_20 } \\
\text { 10,WRI_2018,SDGI_2018,SSIEC_2016,SSIEN_2016,SSIH_2016,LPI_20 } \\
\text { 18,ESI_2005,SPI_2018,GGG_2018,WGI_2013 }\end{array}$ & 18 & 90 \\
\hline WGI_2013 & $\begin{array}{l}\text { Linear } \\
\text { Regression }\end{array}$ & $\begin{array}{l}\text { EI_2013,ENVI_2004,EPI_2018,HDI_2017,HWI_2001,ECF_2016,ECSI_2 } \\
\text { 001,ECVI_2013,EF_2019,EWI_2001,NRPI_2017,CHI_2015,DI_2018,G } \\
\text { DP_20162017,NDGAIN_2017,CPI_2016,CDI_2010,GPI_2019,HSDI_20 } \\
\text { 10,WRI_2018,SDGI_2018,SSIEC_2016,SSIEN_2016,SSIH_2016,LPI_20 } \\
\text { 18,ESI_2005,SPI_2018,GGG_2018,HPI_2016 }\end{array}$ & 22 & 110 \\
\hline
\end{tabular}




\section{Appendix B}

\section{Data transformation (TF) made with results before and after}
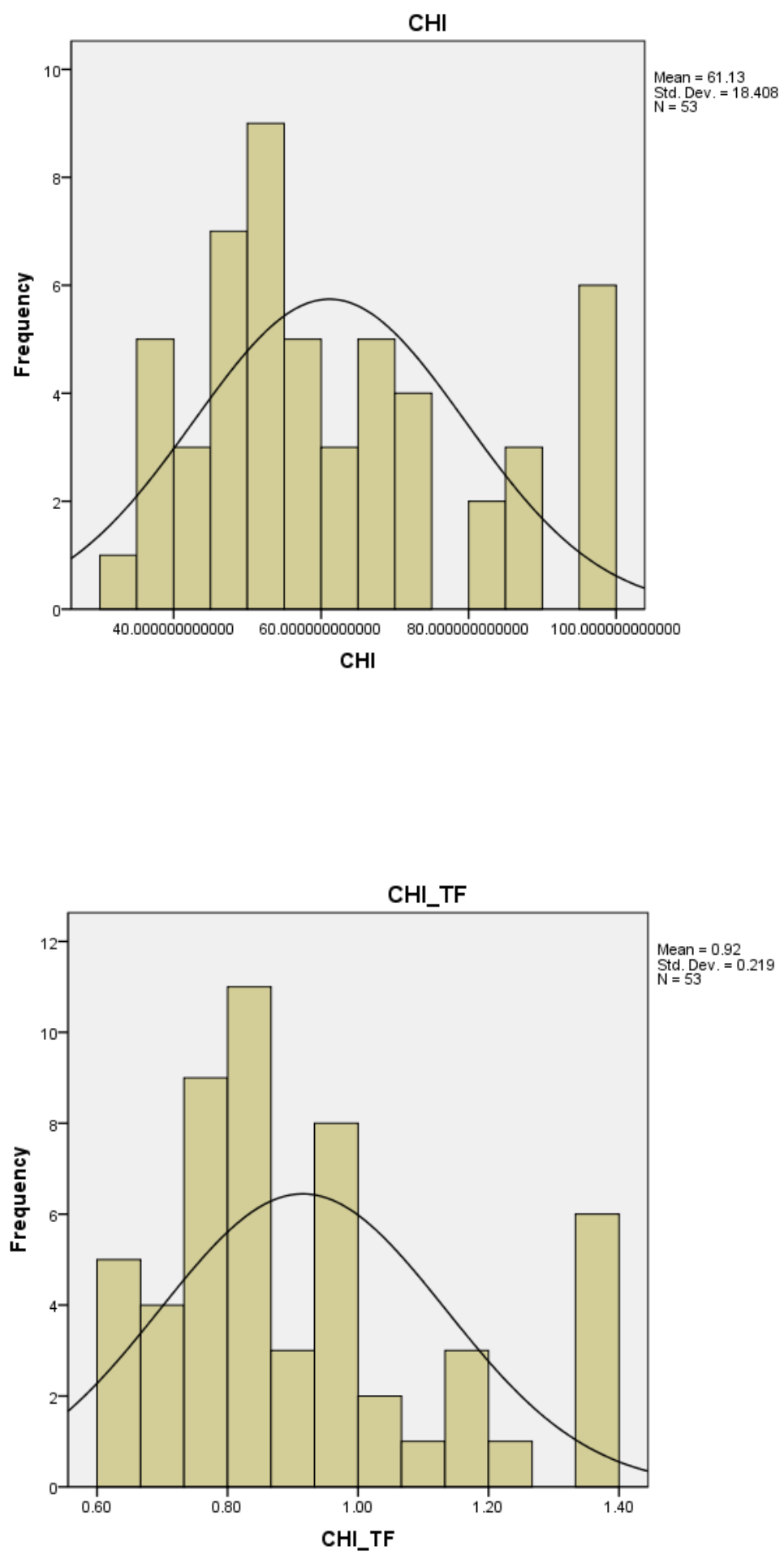

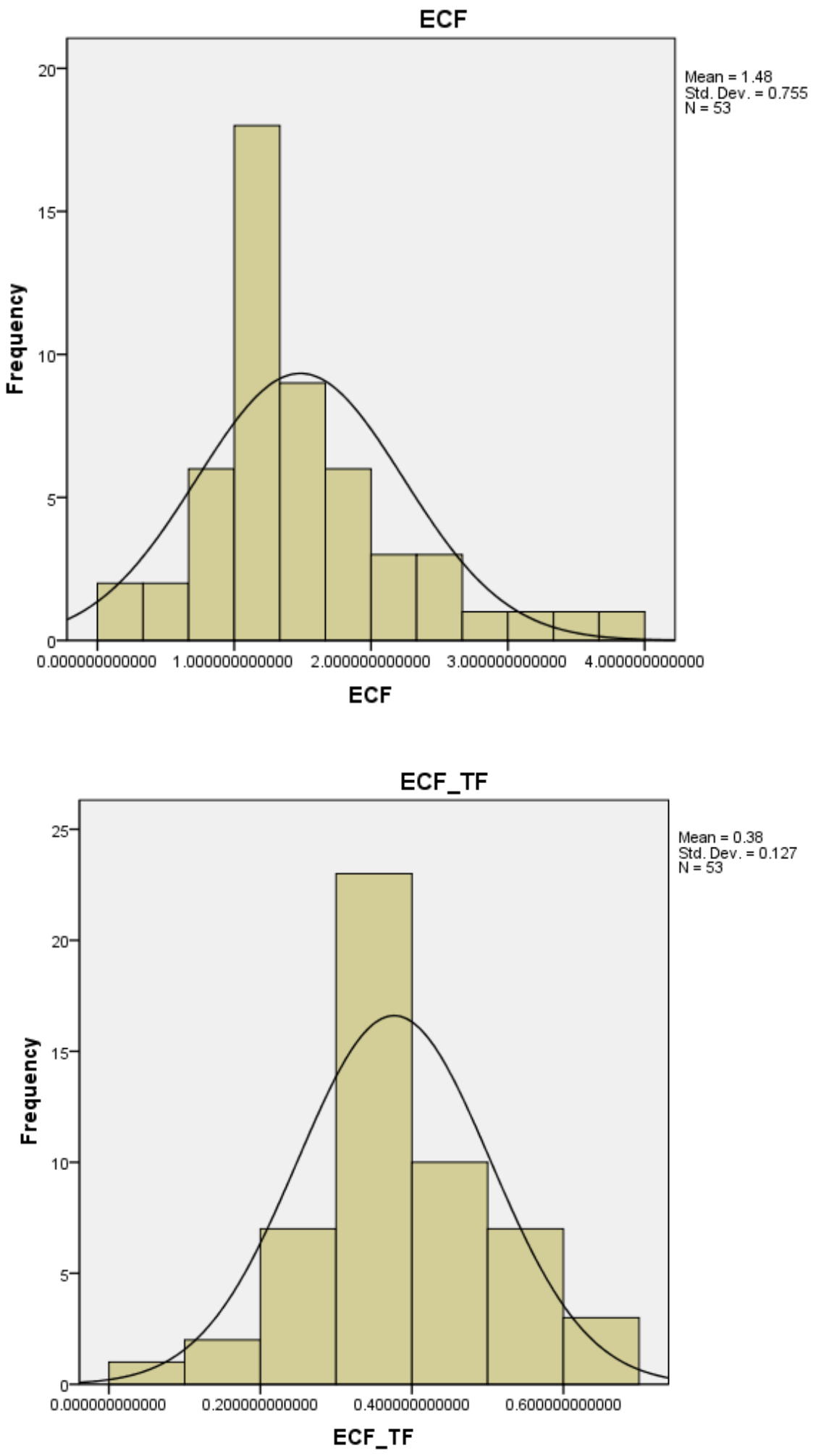

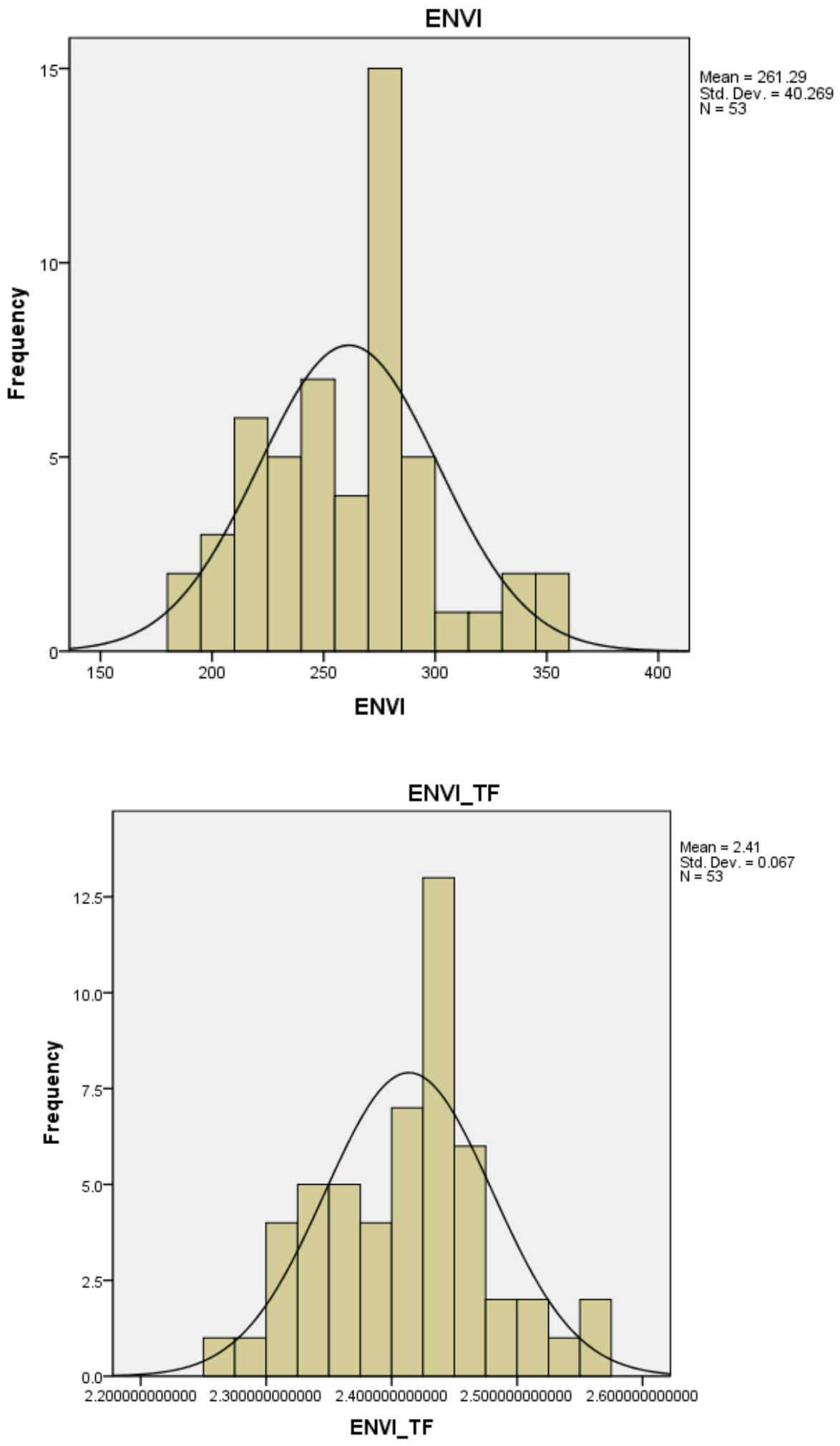

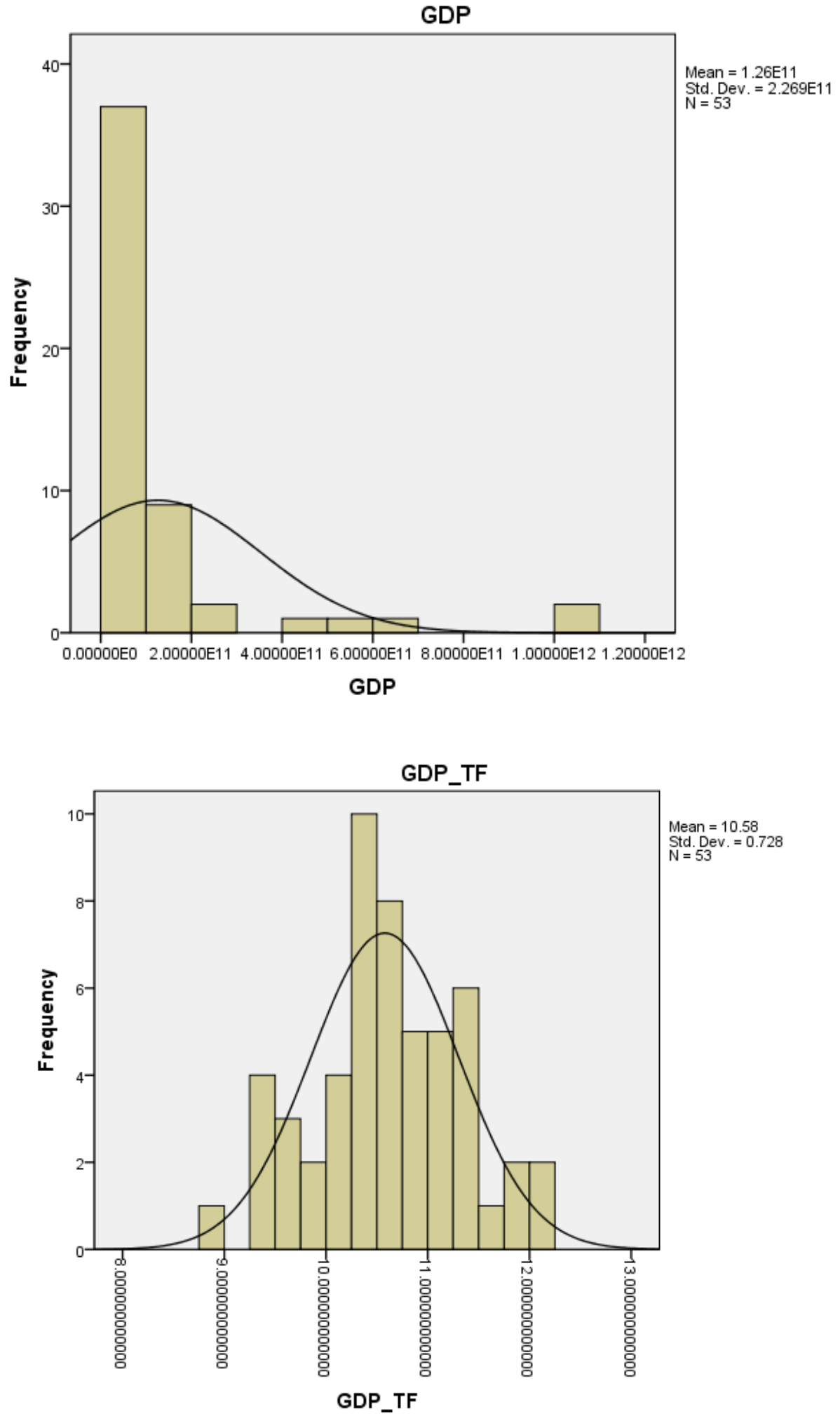

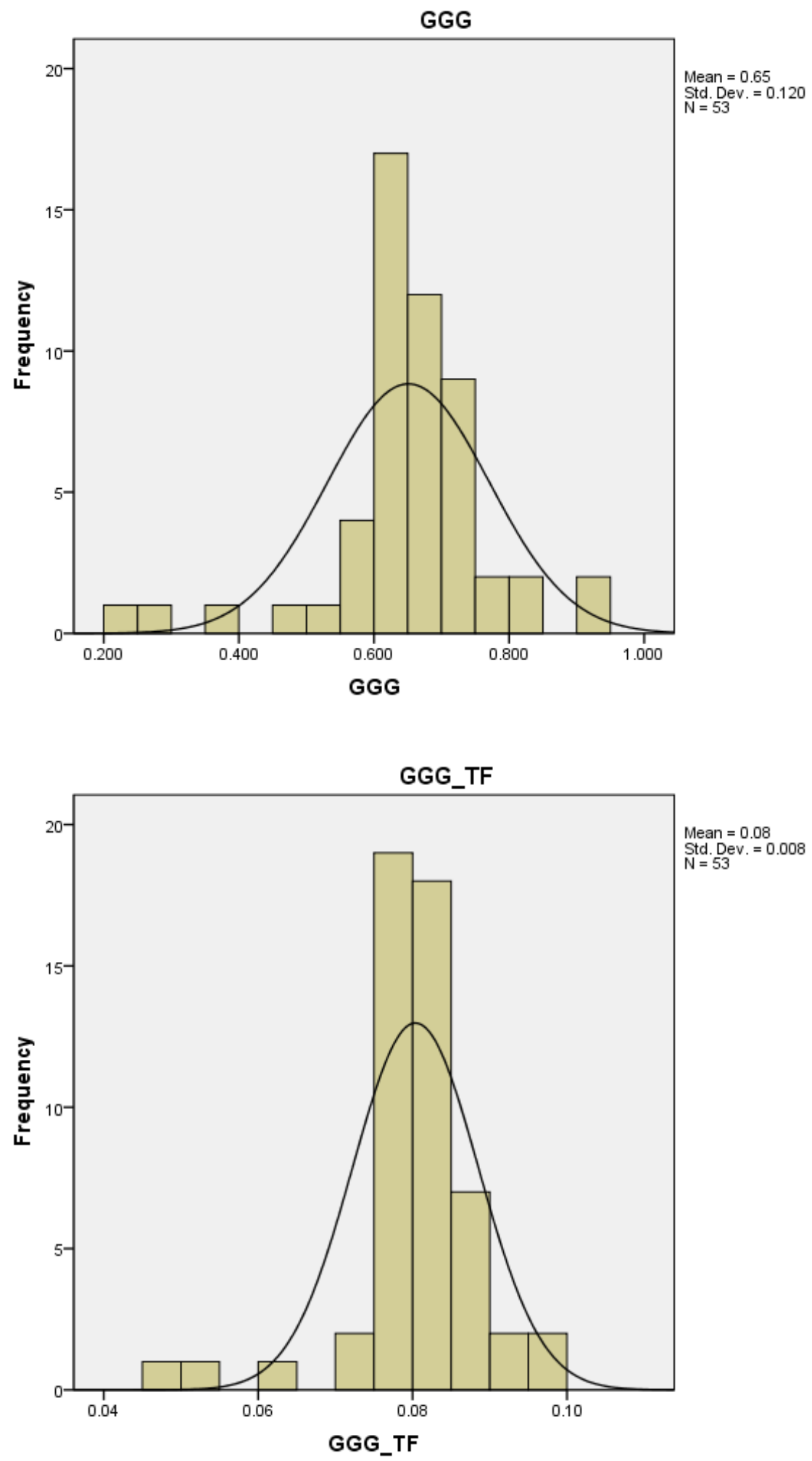

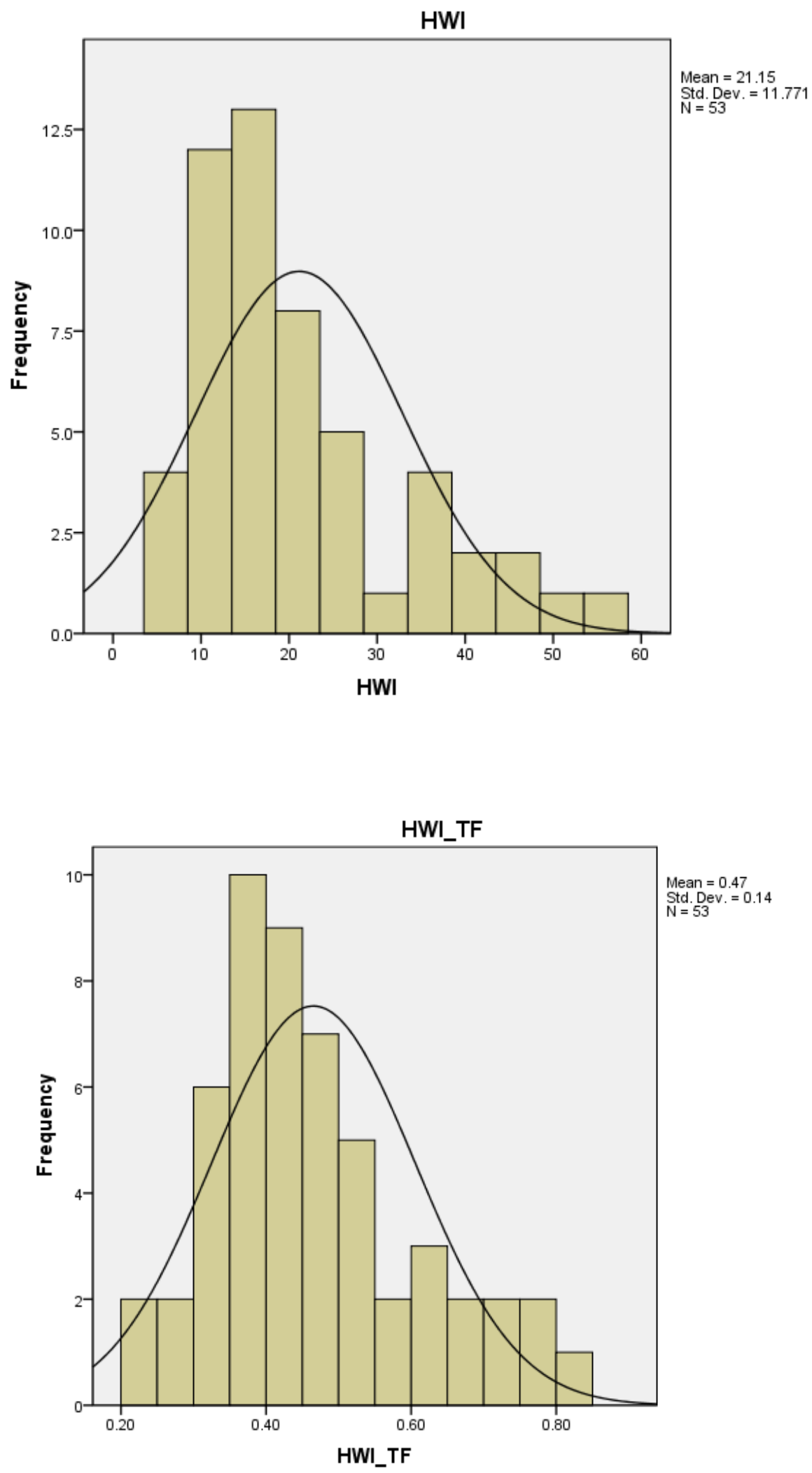

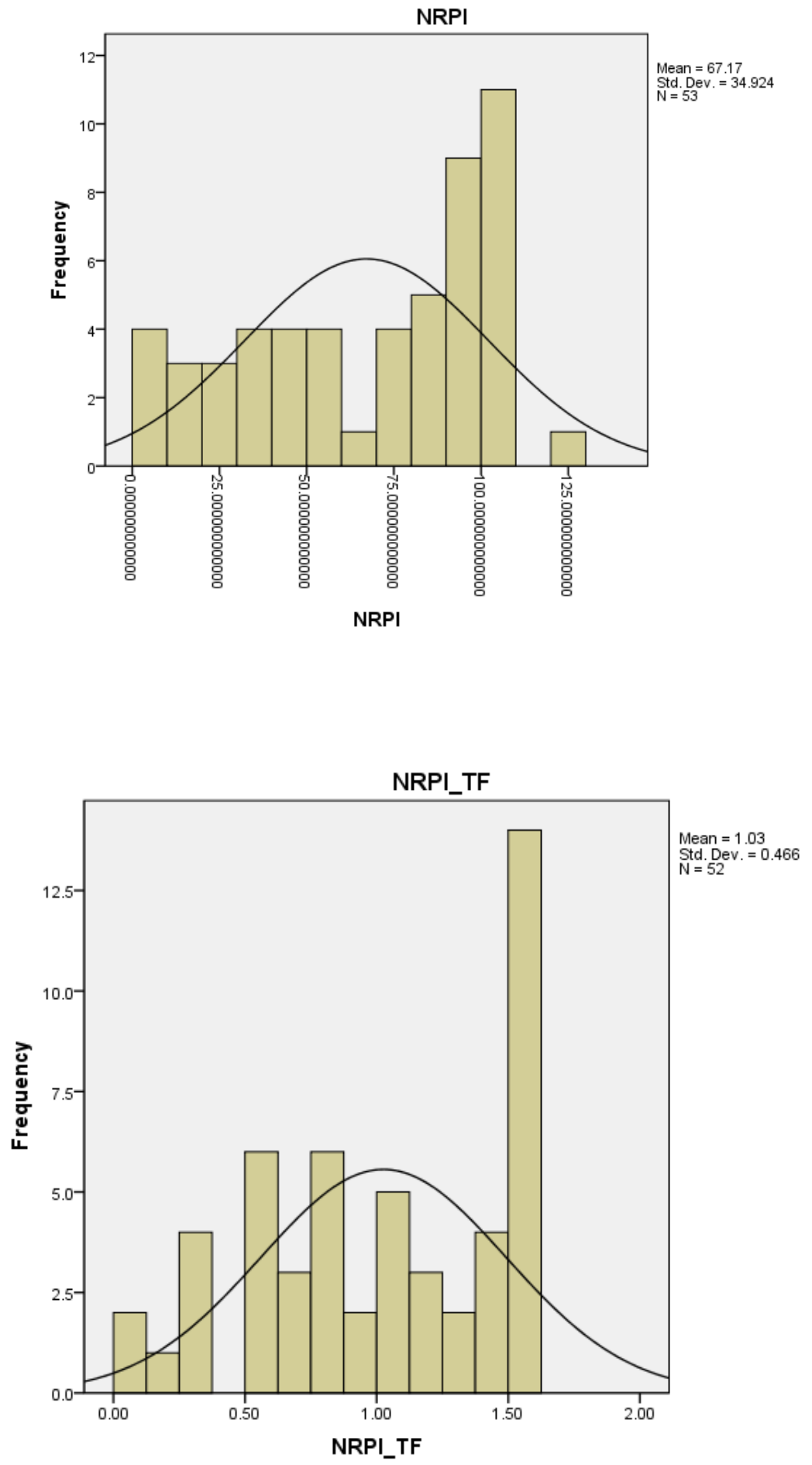

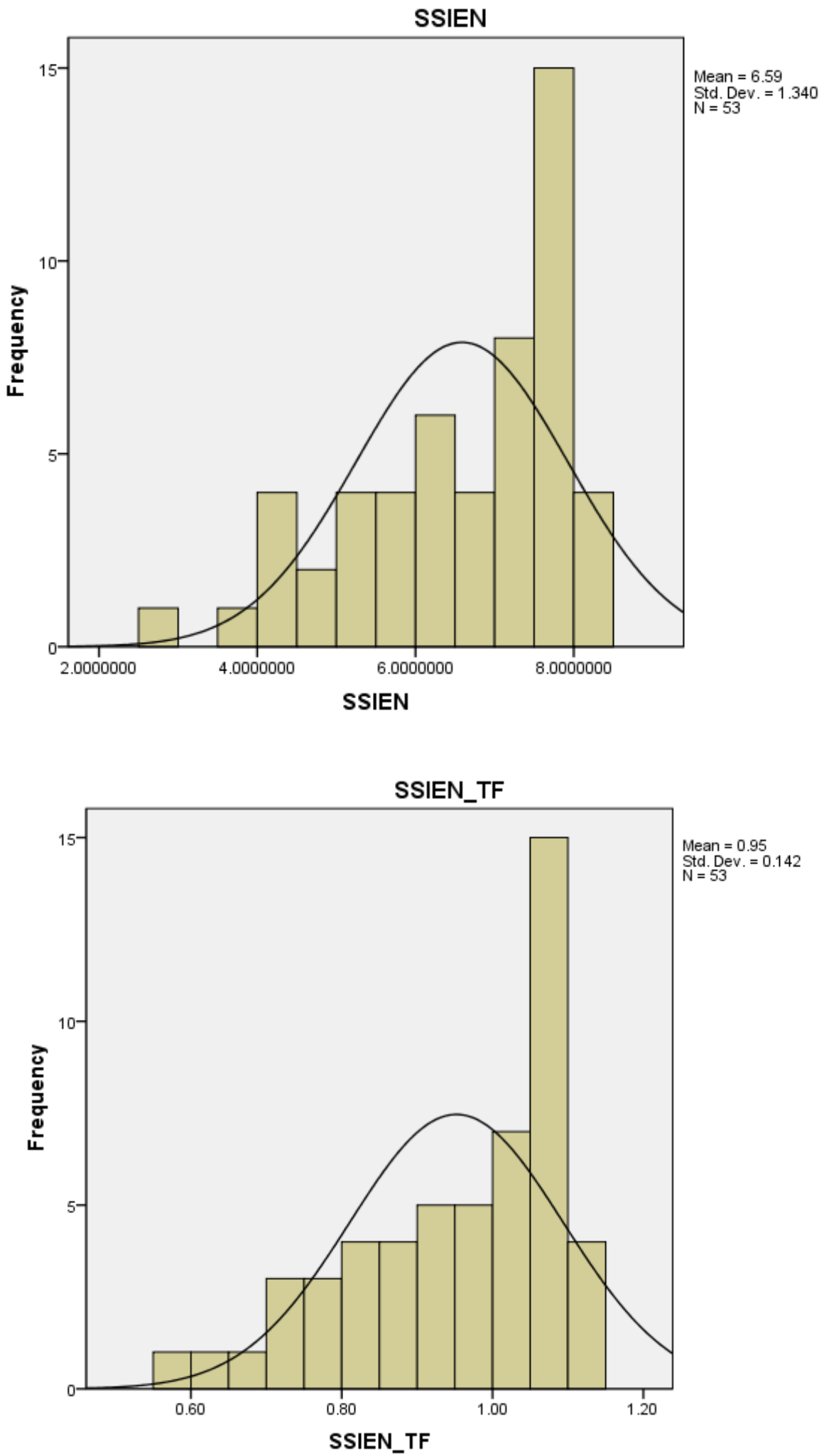


\section{Appendix C}

Detailed results of the factor analysis conducted on JMP

\section{Eigenvalues}

\begin{tabular}{|c|c|c|c|c|}
\hline Number & Eigenvalue & Percent & $\begin{array}{llll}20 & 40 & 60 & 80\end{array}$ & Cum Percent \\
\hline 1 & 12.3953 & 41.318 & & 41.318 \\
\hline 2 & 3.5054 & 11.685 & & 53.002 \\
\hline 3 & 2.1741 & 7.247 & & 60.249 \\
\hline 4 & 1.9327 & 6.442 & & 66.691 \\
\hline 5 & 1.7213 & 5.738 & & 72.429 \\
\hline 6 & 1.3103 & 4.368 & & 76.797 \\
\hline 7 & 0.9637 & 3.212 & & 80.009 \\
\hline 8 & 0.8551 & 2.850 & & 82.859 \\
\hline 9 & 0.7198 & 2.399 & & 85.259 \\
\hline 10 & 0.7135 & 2.378 & & 87.637 \\
\hline 11 & 0.6835 & 2.278 & & 89.915 \\
\hline 12 & 0.5080 & 1.693 & & 91.609 \\
\hline 13 & 0.4666 & 1.555 & & 93.164 \\
\hline 14 & 0.3997 & 1.332 & & 94.496 \\
\hline 15 & 0.2804 & 0.935 & & 95.431 \\
\hline 16 & 0.2656 & 0.885 & & 96.316 \\
\hline 17 & 0.2088 & 0.696 & & 97.012 \\
\hline 18 & 0.1957 & 0.652 & & 97.665 \\
\hline 19 & 0.1551 & 0.517 & & 98.182 \\
\hline 20 & 0.1439 & 0.480 & & 98.661 \\
\hline 21 & 0.0968 & 0.323 & & 98.984 \\
\hline 22 & 0.0746 & 0.249 & & 99.233 \\
\hline 23 & 0.0719 & 0.240 & & 99.472 \\
\hline 24 & 0.0499 & 0.166 & & 99.639 \\
\hline 25 & 0.0309 & 0.103 & & 99.742 \\
\hline 26 & 0.0295 & 0.098 & & 99.840 \\
\hline 27 & 0.0256 & 0.085 & & 99.925 \\
\hline 28 & 0.0131 & 0.044 & & 99.969 \\
\hline 29 & 0.0094 & 0.031 & & 100.000 \\
\hline
\end{tabular}


Scree Plot

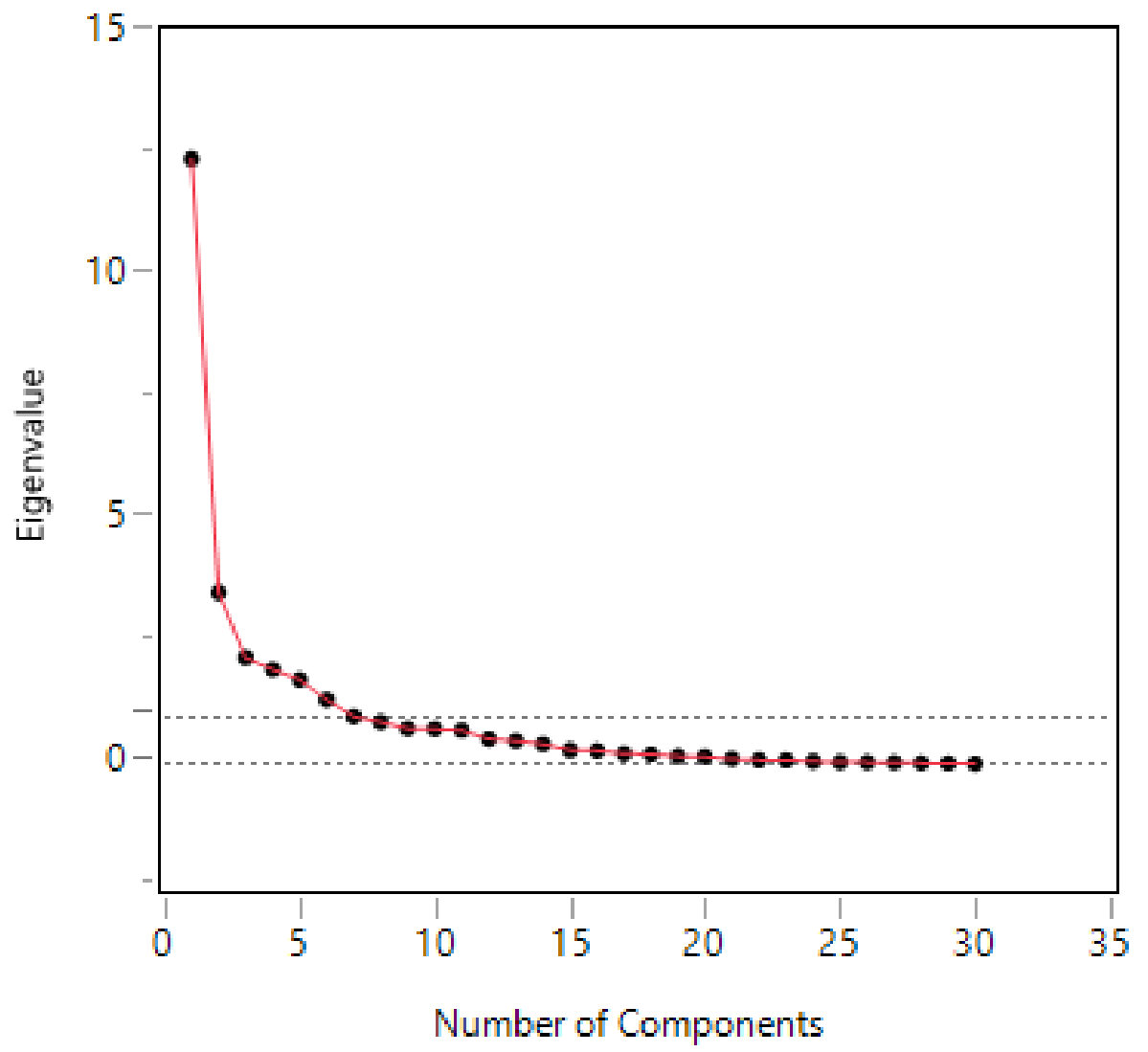




\section{Final Communality Estimates 6 Factors, Principal Axis / Varimax}

$\begin{array}{ll}\text { CDI } & 0.72484 \\ \text { CHI_TF } & 0.78448 \\ \text { CPI } & 0.82030 \\ \text { DI } & 0.83017 \\ \text { ECF_TF } & 0.57190 \\ \text { ECSI } & 0.85751 \\ \text { ECVI } & 0.63990 \\ \text { EF } & 0.79264 \\ \text { EI } & 0.83651 \\ \text { ENVI_TF } & 0.46915 \\ \text { EPI } & 0.68394 \\ \text { ESI } & 0.76991 \\ \text { EWI } & 0.85751 \\ \text { GDP_TF } & 0.72732 \\ \text { GGG_TF } & 0.73040 \\ \text { GPI } & 0.82584 \\ \text { HDI } & 0.89088 \\ \text { HPI } & 0.78534 \\ \text { HSDI } & 0.92904 \\ \text { HWI_TF } & 0.83387 \\ \text { LPI } & 0.84780 \\ \text { NDGAIN } & 0.86261 \\ \text { NRPI_TF } & 0.72392 \\ \text { SDGI } & 0.83157 \\ \text { SPI } & 0.94643 \\ \text { SSIEC } & 0.63632 \\ \text { SSIEN_TF } & 0.73953 \\ \text { SSIH } & 0.78632 \\ \text { WGI } & 0.77343 \\ \text { WRI } & 0.52958\end{array}$

Variance Explained by Each Factor Factor Variance Percent Cum Percent $\begin{array}{llll}\text { Factor } 1 & 8.4188 & 28.063 & 28.063\end{array}$ $\begin{array}{llll}\text { Factor } 2 & 4.7978 & 15.993 & 44.055\end{array}$ $\begin{array}{llll}\text { Factor } 3 & 3.0918 & 10.306 & 54.361\end{array}$ $\begin{array}{llll}\text { Factor } 4 & 2.4621 & 8.207 & 62.568\end{array}$ $\begin{array}{llll}\text { Factor } 5 & 2.1513 & 7.171 & 69.739\end{array}$

$\begin{array}{llll}\text { Factor } 6 & 2.1173 & 7.058 & 76.797\end{array}$




\begin{tabular}{|c|c|c|c|c|c|c|}
\hline \multicolumn{7}{|c|}{ Rotated Factor Loading } \\
\hline & & $\operatorname{tac}$ & & & & 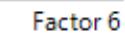 \\
\hline HSDI & & & & & & \\
\hline $\mathrm{HDI}$ & 0.899 & & -0.060 & 0.047608 & -0.097320 & 0.158511 \\
\hline El & 0 & & -0. & 0.1 & -0 & -0.018 \\
\hline CHI_TF & 0.81 & & -0.257757 & -0.033294 & -0.08 & \\
\hline SDGI & & & -0.209209 & 0.053179 & & 0.370567 \\
\hline SPI & & & & & & \\
\hline SSIH & & & & & & \\
\hline & & & & & & \\
\hline & & & & & & \\
\hline ECF_T & & & & & & \\
\hline ECSI & & & & & & \\
\hline $\mathrm{DI}$ & & & & & & \\
\hline CPI & & & & & & \\
\hline EF & & & & & & \\
\hline LPI & & & & & & \\
\hline ESI & & & & & & \\
\hline & & & & & & \\
\hline EWI & & & & & & \\
\hline & & & & & & \\
\hline & & & & & & \\
\hline & & & & & & \\
\hline WR & -0.0 & & & & & \\
\hline GP & & 02 & & 0.2 & & \\
\hline WG & & & & -0.0 & & \\
\hline ECV & & & & & 322 & \\
\hline $\mathrm{CDI}$ & & & & & & \\
\hline $\mathrm{HP}$ & & & & & & \\
\hline EPI & & & & & -0.008362 & 0.574227 \\
\hline & & & & & & \\
\hline & -0.021915 & -0.005075 & 0.023373 & -0.850586 & -0.068082 & 0034010 \\
\hline
\end{tabular}

Suppress Absolute Loading Value Less Than 0.3 Dim Text 0.4

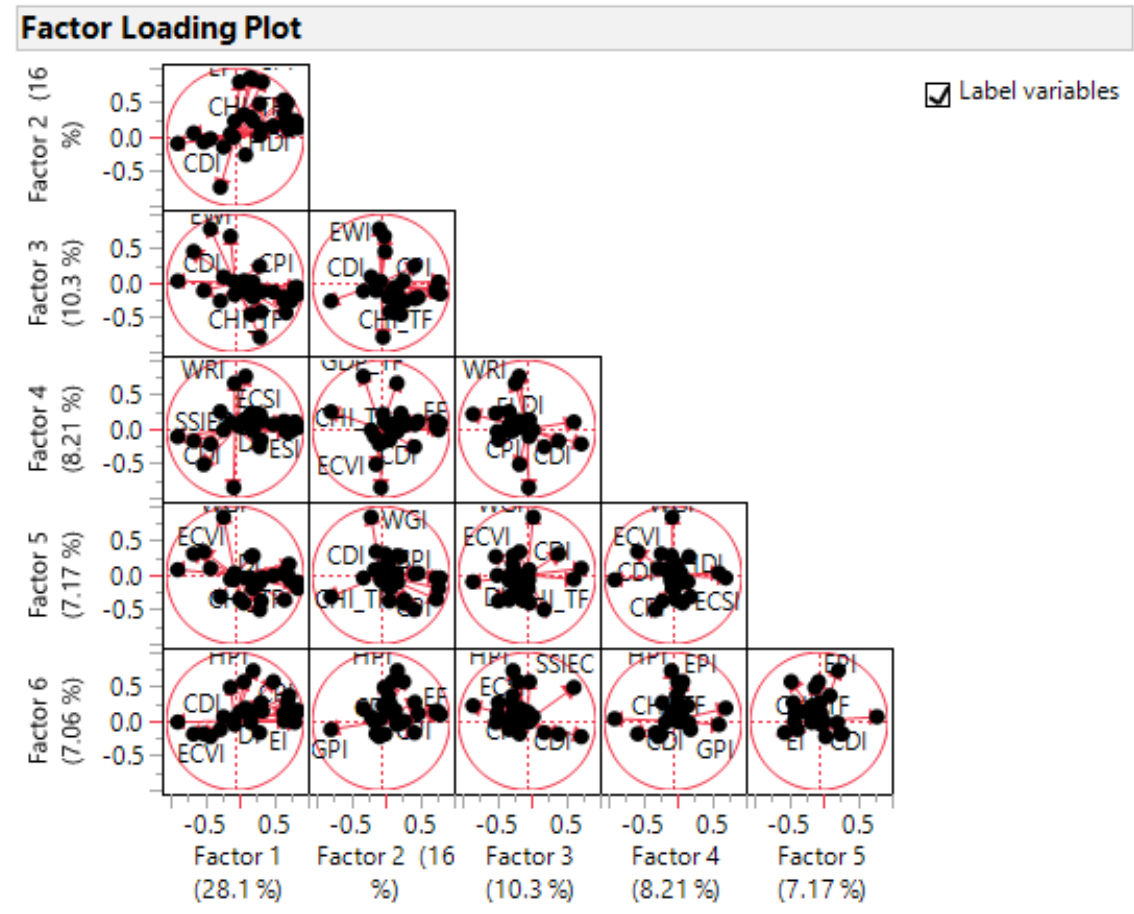




\section{References}

Anselin, L. (1995). Local indicators of spatial association - LISA. Wiley Online Library, 27(2). Retrieved from https://agupubs.onlinelibrary.wiley.com/doi/abs/10.1111/j.15384632.1995.tb00338.x

Bilgili, F., \& Ulucak, R. (2018). Is there deterministic, stochastic, and/or club convergence in ecological footprint indicator among G20 countries? Environmental Science and Pollution Research, 25(35), 35404-35419. doi:10.1007/s11356-018-3457-1

BEH - Bundnis Entwicklung Hilft. (2018). World Risk Report. Retrieved August 4, 2019, from: https://weltrisikobericht.de/english-2/

CIESIN - Center for International Earth Science Information Network, Columbia University. (2015). Natural resource Protection and Health Indicators. Retrieved April 10, 2019, from: https://sedac.ciesin.columbia.edu/data/set/nrmi-natural-resource-protectionchild-health-indicators-2015/data-download

CAF - Charities Aid Foundation. (2013). World Giving Index. Retrieved June 4, 2019, from: https://www.cafonline.org/about-us/publications/2013-publications/world-givingindex-2013

Chichilnisky, G. (1997). What is sustainable development? Land Economics, 73(4), 467-491. doi:10.2307/3147240

Dialga, I. (2018). A sustainability index of mining countries. Journal of Cleaner Production, 179, 278-291. doi:10.1016/j.jclepro.2017.12.185

EIU - Economist Intelligence Unit, (2018). The Economist Intelligence Unit's Democracy Index. Retrieved April 6, 2019 from:

https://www.eiu.com/public/topical_report.aspx?campaignid=Democracy2018

ESRI - Environmental Systems Research Institute, 2017. ArcGIS 10.6.3. Released 2017.

Computer Software, Redlands, CA

GADM - Global Administrative Areas, (2018). GADM Database of Global Administrative Areas. Version 3.6 Retrieved January 10, 2019, from: http://www.gadm.org/. 
GFN - Global Footprint Network. (2016). Ecological Footprint. Retrieved April 15, 2019, from http://data.footprintnetwork.org/\#/compareCountries?type=EFCpc\&cn=all\&yr=2016

Gottlieb, R. (1993). Forcing the Spring: The Transformation of the American Environmental Movement California Island Press

Hansmann, R., Mieg, H. A., \& Frischknecht, P. (2012). Principal sustainability components: Empirical analysis of synergies between the three pillars of sustainability. International Journal of Sustainable Development \& World Ecology, 19(5), 451-459. Retrieved September 12, 2019, from: doi:10.1080/13504509.2012.696220

HPI - Happy Planet Index. (2016). Happy Planet Index. Retrieved April 15, 2019, from: http://happyplanetindex.org/

Huang, L., Wu, J., \& Yan, L. (2015). Defining and measuring urban sustainability: A review of indicators. Landscape Ecology, 30(7), 1175-1193. Retrieved September 12, 2019, from: doi:10.1007/s10980-015-0208-2

IEP - Institute of Economic \& Peace. (2019). Global Peace Index. Retrieved June 5, 2019, from: http://visionofhumanity.org/app/uploads/2019/07/GPI-2019web.pdf

Heritage. (2019). Index of Economic Freedom. Retrieved April 20, 2019, from https://www.heritage.org/index/explore

Lee, Y., \& Huang, C. (2007). Sustainability index for Taipei. Environmental Impact Assessment Review, 27(6), 505-521. doi:10.1016/j.eiar.2006.12.005

LI - Legatum Institute. (2018). The Legatum Prosperity Index. Retrieved April 20, 2019, from: https://www.prosperity.com/about/resources

Malbert, Bjorn (1998) Participatory Approaches Sustainable Urban Development: Reflections on Practice Vancouver and Waitakere to in Seattle, Planning Practice \& Research, 13:2, 183189, Retrieved September 11, 2019 from: DOI: 10.1080/02697459816184

Mascarenhas, A., Nunes, L. M., \& Ramos, T. B. (2015). Selection of sustainability indicators for planning: Combining stakeholders' participation and data reduction techniques. Journal of Cleaner Production, 92, 295-307. Retrieved September 12, 2019, From: doi:10.1016/j.jclepro.2015.01.005 
Melecky, L. (2015). Spatial Autocorrelation Method for Local Analysis of the EU. Procedia Economics and Finance, Retrieved April 2, 2019, from https://doi.org/10.1016/S22125671(15)00484-0

NDAll - Notre Dame Adaption Initiative Index. (2017). Retrieved April 2, 2019, from University of Notre Dame: https://gain.nd.edu/our-work/country-index/

O'Reilly, Neal; Ehlinger, Timothy; and Shaker, Richard, "The Development and Evaluation of Methods for Quantifying Risk to Fish in Warm-water Streams of Wisconsin Using SelfOrganized Maps: Influences of Watershed and Habitat Stressors" (2007). Center for Urban Environmental Studies Publications, Retrieved July 30, 2019, from: rrshaker.com/rrs/publications_files/The\%20Development\%20and\%20Evaluation\%20of \%20Methods\%20for\%20Quantifying\%20Risk\%20to.pdf

OW - Our World. (2010). Human Sustainable Development Index. Retrieved April 15, 2019, from: https://i.unu.edu/media/ourworld.unu.edu-en/article/2608/2010-HumanSustainable-Development-Index.pdf

Pezzoli, Keith. (1997). Sustainable Development: A Transdisciplinary Overview of the Literature, Journal of Environmental Planning and Management retrieved September 11, 2019, from:

https://www.academia.edu/2297216/Sustainable_Development_A_Transdisciplinary_O verview_of_the_Literature

Pissourios, I. A. (2013). An interdisciplinary study on indicators: A comparative review of qualityof-life, macroeconomic, environmental, welfare and sustainability indicators. Ecological Indicators, 34, 420-427. Retrieved April 5, 2019 from: doi:10.1016/j.ecolind.2013.06.008

Prescott-Allen, R. (2001). The wellbeing of nations: A country-by-country index of quality of life and the environment. Washington: Island Press.

REVI - Retrospective Economic Vulnerability Index. (2016, March). Retrieved April 20, 2019, from http://www.ferdi.fr/en/indicator/retrospective-economic-vulnerability-index 
SAS - SAS Institute Incorporated, 2018. JMP Statistical Discovery. Version 14.3.0. Released 2018. Cary, NC, USA.

SCF - Save The Children Fund. Retrieved April 10, 2019, from Child Development Index:

Progress, Challenges and Inequality

https://resourcecentre.savethechildren.net/library/child-development-index-2012progress-challenges-and-inequality

Schlenker, W., \& Lobell, D. B. (2010). Robust negative impacts of climate change on African agriculture. Environmental Research Letters, 5(1), 014010. doi:10.1088/1748$9326 / 5 / 1 / 014010$

Shaker, R. R. (2015). Corrigendum to "the spatial distribution of development in Europe and its underlying sustainability correlations" [applied geography vol. 63, September 2015, 304314]. Applied Geography, 65, 109. doi:10.1016/j.apgeog.2015.11.013

Shaker, R. R. (2018). A mega-index for the Americas and its underlying sustainable development correlations. Ecological Indicators, 89, 466-479. doi:10.1016/j.ecolind.2018.01.050

SDAC - Socioeconomic Data and Applications Center. (2004). Environmental Vulnerability Index Retrieved April 13, 2019, from: https://sedac.ciesin.columbia.edu/data/set/cesicenvironmental-vulnerability-index-2004/data-download

SDAC - Socioeconomic Data and Applications Center. (2005). Environmental Sustainability Index Retrieved April 20, 2019, from: https://sedac.ciesin.columbia.edu/data/set/esienvironmental-sustainability-index-2005/data-download

SDAC - Socioeconomic Data and Applications Center. (2017). Natural Resource Protection Index. Retrieved April 15, 2019, from: https://sedac.ciesin.columbia.edu/data/set/nrminatural-resource-protection-child-health-indicators-2017/data-download

SDAC - Socioeconomic Data and Applications Center. (2018). Environmental Performance Index. Retrieved April 13, 2019, from: https://sedac.ciesin.columbia.edu/data/set/epienvironmental-performance-index-2018/data-download 
SPI - Social Progress Imperative. (2018). Social Progress Index Retrieved April 13, 2019, from: https://www.socialprogress.org/

Steiner, G., \& Posch, A. (2006). Higher education for sustainability by means of transdisciplinary case studies: An innovative approach for solving complex, real-world problems. Journal of Cleaner Production, 14(9), 877-890. Retrived September 12, 2019, from: doi:10.1016/j.jclepro.2005.11.054

SDGI - Sustainable Development Goals Index. (2018). Retrieved April 16, 2019, from: https://www.sdgindex.org/reports/2018/

SSIEC - Sustainable Society Index - Economic Wellbeing. (2016). Retrieved April 13, 2019, from: http://www.ssfindex.com/data-all-countries/

SSIEN - Sustainable Society Index - Environmental Wellbeing. (2016). Retrieved April 13, 2019, from: http://www.ssfindex.com/data-all-countries/

SSIH - Sustainable Society Index - Human Wellbeing. (2016). Retrieved April 13, 2019, from: http://www.ssfindex.com/data-all-countries/

WB - The World Bank. (2017). GDP Data. Retrieved April 2, 2019, from: https://data.worldbank.org/

Tanguay, G. A., Rajaonson, J., Lefebvre, J., \& Lanoie, P. (2010). Measuring the sustainability of cities: An analysis of the use of local indicators. Ecological Indicators, 10(2), 407-418. Retrieved September 11, 2019 from: doi:10.1016/j.ecolind.2009.07.013

TI - Transparency International (2016). Corruption Perceptions Index. Retrieved April 15, 2019, from https://www.transparency.org/news/feature/corruption_perceptions_index_2016\#reso urces

Turcu, C. (2013). Re-thinking sustainability indicators: Local perspectives of urban sustainability. Journal of Environmental Planning and Management, 56(5), 695-719. Retrieved September 11, 2019 from: doi:10.1080/09640568.2012.698984 
UNDP - United Nation Development Programme. (2013, November 15). Human Development Report Education Index Retrieved May 10, 2019, from: http://hdr.undp.org/en/content/education-index

UNDP - United Nations Development Programme. (2017). Human Development Report Human Development Index. Retrieved April 20, 2019, from: http://hdr.undp.org/en/composite/HDI

UN - United Nations, 1992. Agenda 21: The United Nations Programme of Action Agenda 21 Retrieved September 11, 2019 from: https://sustainabledevelopment.un.org/outcomedocuments/agenda21

Verma, P., \& Raghubanshi, A. S. (2018). Urban sustainability indicators: Challenges and opportunities. Ecological Indicators, 93, 282-291. doi:10.1016/j.ecolind.2018.05.007

Worldatlas. (2016, September 9). Retrieved from Africa: https://www.worldatlas.com/webimage/countrys/af.htm\#page WCED - World Commission on Environment and Development, (1987). Our Common Future. Oxford University Press, Oxford, UK. Retrieved September 11, 2019, from: https://sustainabledevelopment.un.org/content/documents/5987our-commonfuture.pdf

WEF - World Economic Forum. (2018). Global Gender Gap Report. Retrieved August 4, 2019, from: http://reports.weforum.org/global-gender-gap-report-2018/results-andanalysis/?doing_wp_cron=1566240364.1525099277496337890625 